LBL -35155

UC -311

\title{
Recovery of Propylene Glycol from Dilute Aqueous Solutions via Reversible Reaction with Aldehydes
}

\author{
Robert R. Broekhuis \\ Scott Lynn \\ C. Judson King \\ Department of Chemical Engineering \\ University of California \\ and \\ Energy and Environment Division \\ Lawrence Berkeley Laboratory \\ University of California \\ Berkeley, CA 94720
}

December 1993

This work was supported by the Assistant Secretary for Conservation and Renewable Energy, Office of Industrial Technologies, Advanced Industrial Concepts Division of the U. S. Department of Energy under Contract No. DE-AC03-76SF00098. 


\title{
Recovery of Propylene Glycol from Dilute Aqueous Solutions via Reversible Reaction with Aldehydes
}

\author{
Robert R. Broekhuis \\ C. Judson King
}

Scott Lynn

\begin{abstract}
A means is proposed for separating propylene glycol and other compounds bearing multiple hydroxyl groups by reversible chemical reaction. Glycols react with aldehydes in cyclic acetalization reactions to form substituted dioxolanes. Propylene glycol reacts with formaldehydeand acetaldeh yde to form 4-methyl-1,3-dioxolaneand 2,4-dimethyl-1,3-dioxolane, respectively. The reaction is catalyzed homogeneously by strong mineral acids or heterogeneously by cation exchange resins in the acid form. Separation processes utilizing this reaction would include an acetalization step, several distillative separation steps and finally a hydrolysis step in which the reaction is reversed. Both reaction steps must be forced to completion by removing the reaction product simultaneously.

The equilibrium and kinetics of the reaction with formaldehyde were studied experimentally in systems catalyzed by Amberlite IR-120 ion exchange resin. The equilibrium constant for acetalization ranged from 5.9 to 8.7 in the temperature range 25 to $85^{\circ} \mathrm{C}$, with no obvious trend in temperature. The kinetics was found to be first-order in the concentrations of propylene glycol, formaldehyde and Amberlite IR-120. The activation energy was found to be $101 \mathrm{~kJ} / \mathrm{mol}$ in the temperature range 80 to $100^{\circ} \mathrm{C}$. In the reaction with acetaldehyde, the equilibrium constant decreased with increasing temperature from 18.1 at $40^{\circ} \mathrm{C}$ to 8.5 at $83^{\circ} \mathrm{C}$, indicating an exothermic reaction with an average heat of reaction of $-11.5 \mathrm{~kJ} / \mathrm{mol}$ over that temperature range. The kinetics of the reaction with acetaldehyde was faster than with formaldehyde. The relative volatilities of 4-methyl-1,3-dioxolane and 2,4-dimethyl-1,3dioxolane in aqueous solution, measured in an Othmer still, were 100 and 33 , respectively. A
\end{abstract}


number of solvents were screened for their ability to extract 2,4-dimethyl-1,3-dioxolane from aqueous solution. Of the solvents screened, aromatic hydrocarbons exhibited the highest distribution into the organic phase. The vapor-liquid equilibrium in the system toluene - 2,4dimethyl-1,3-dioxolane, measured in an Othmer still, was well described by an ideal binary mixture with a relative volatility of 1.76 .

To achieve an effective separation of propylene glycol from aqueous solution by combined reaction with formaldehyde and distillation, formaldehyde would have to be present in excess and would be difficult and costly to separate from the aqueous solution. In reactive distillation using acetaldehyde as a reactant this is not a problem due to its high relative volatility. A large flow of acetaldehyde would be necessary to recover the propylene glycol to a sufficient degree in a distillative process, since the concentration of acetaldehyde in the liquid phase would be low. In a process combining reaction and extraction into an organic solvent this problem is avoided. Process simulation indicates that the energy input of such a process is less than half of the energy required in a triple-effect evaporation process. This benefit is offset to some extent by higher capital costs and increased complexity in the reaction/extraction process. 
Table of contents

1. Introduction $\ldots \ldots \ldots \ldots \ldots \ldots \ldots \ldots \ldots \ldots \ldots \ldots \ldots \ldots \ldots \ldots \ldots$

1.1. Recovery of hydroxylated compounds from aqueous solutions $\ldots \ldots \ldots \ldots \ldots 1$

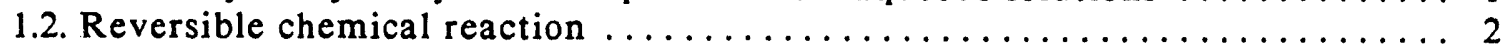

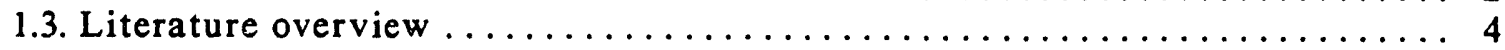

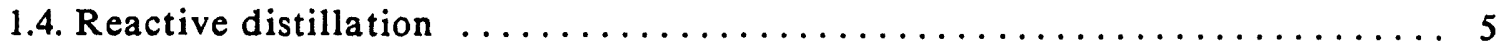

1.5. Simultaneous reaction and extraction ....................... 7

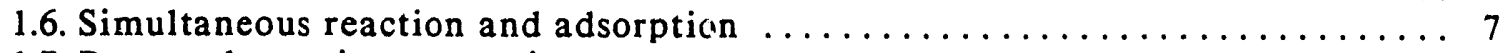

1.7. Proposed reactive separation processes $\ldots \ldots \ldots \ldots \ldots \ldots \ldots \ldots \ldots \ldots$

1.7.1. The distillative formaldehyde process $\ldots \ldots \ldots \ldots \ldots \ldots \ldots . \ldots$

1.7.2. The distillative acetaldehyde process $\ldots \ldots \ldots \ldots \ldots \ldots \ldots \ldots \ldots . \ldots \ldots$

1.7.3. The extractive acetaldehyde process $\ldots \ldots \ldots \ldots \ldots \ldots \ldots \ldots$

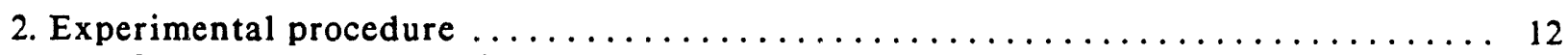

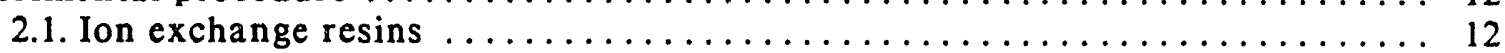

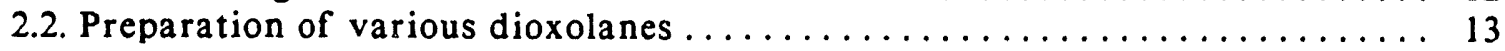

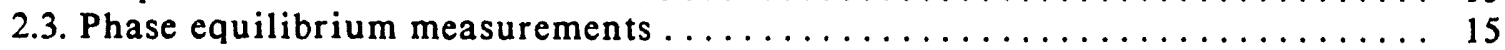

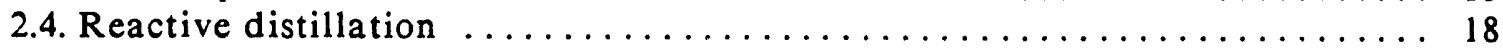

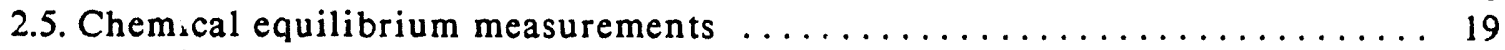

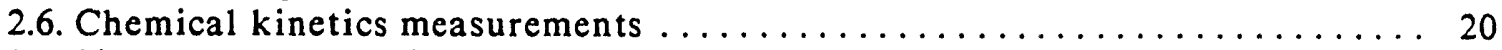

2.7. Simultaneous reaction and extraction experiment $\ldots \ldots \ldots \ldots \ldots \ldots \ldots 21$

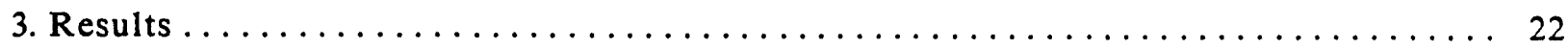

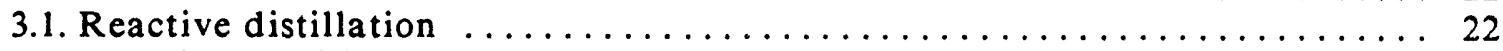

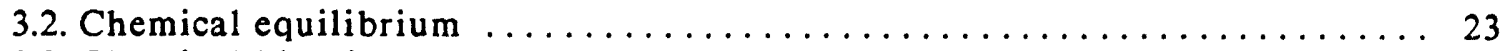

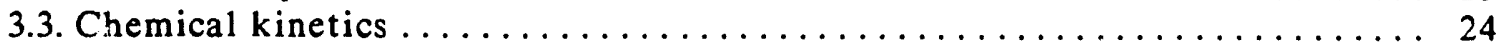

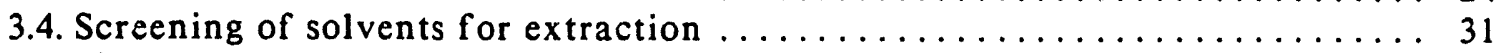

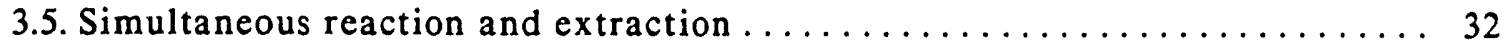

3.6. Liquid-liquid equilibria in dioxolane-water systems $\ldots \ldots \ldots \ldots \ldots \ldots \ldots 33$

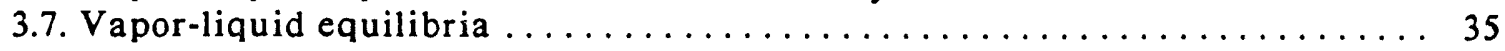

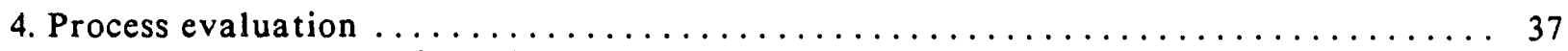

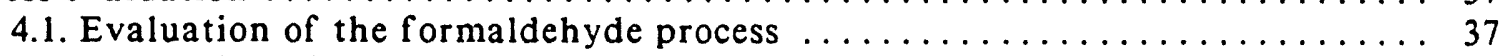

4.2. Evaluation of the acetaldehyde process - distillative route $\ldots \ldots \ldots \ldots \ldots 38$

4.3. Evaluation of the acetaldehyde process - extractive route ........... 39

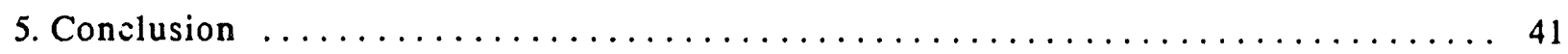

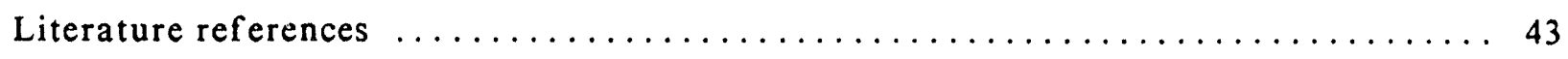

Appendix A. Chemicals used in experimental work $\ldots \ldots \ldots \ldots \ldots \ldots \ldots \ldots \ldots$

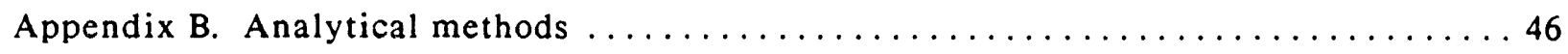

Appendix C. Experimental vapor-liquid equilibrium data $\ldots \ldots \ldots \ldots \ldots \ldots \ldots$

Appendix D. ChemCad process modeling $\ldots \ldots \ldots \ldots \ldots \ldots \ldots \ldots \ldots \ldots \ldots \ldots \ldots \ldots \ldots \ldots \ldots \ldots$

Appendix E. Continuous extraction modelling $\ldots \ldots \ldots \ldots \ldots \ldots \ldots \ldots \ldots \ldots \ldots \ldots \ldots \ldots$ 


\section{List of figures}

Figure 1-1. Flow schematic of the reactive distillation process with formaldehyde. (1) Acetalization column; (2) Transacetalization column; (3) Methylal hydrolysis column; (4) Glycol purification column. ....................... 8

Figure 1-2. Flow schematic of the reactive distillation process with acetaldehyde. (1) Acetalization column; (2) Hydrolysis column; (3) Glycol purification column. . ... 10

Figure 1-3. Flow schematic of the extractive acetaldehyde process. (1) Continuous countercurrent contactor/reactor; (2) and (3) Acetaldehyde stripping columns;

(4) Dioxolane recovery column; (5) Hydrolysis column. ............... 11

Figure 2-1. Diagram of the Othmer still used for VLE measurements. $\ldots \ldots \ldots \ldots \ldots 16$

Figure 2-2. Comparison of two VLE measurements in the ethanol/water system with

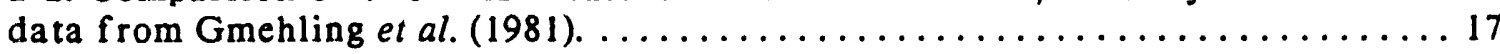

Figure 3-1. Equilibrium constants for the formation of 4-methyl-1,3-dioxolane from 1,2propanediol and formaldehyde, $v s$. temperature. . . . . . . . . . . . . 23

Figure 3-2. Equilibrium constants for the formation of 2,4-dimethyl-1,3-dioxolane from 1,2-propanediol and acetaldehyde, vs. temperature. ................ 25

Figure 3-3. Kinetics of the reaction between 1,2-propanediol and formaldehyde to form

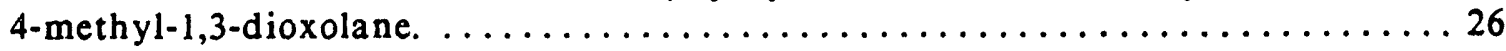

Figure 3-4. Initial reaction rate vs. the product of initial reactant concentrations . . . . 27

Figure 3-5. Arrhenius plot for the 4-methyl-1,3-dioxolane formation reaction $\ldots \ldots \ldots 28$

Figure 3-6. Kinetics of the reaction between 4-methyl-1,3-dioxolane and methanol to

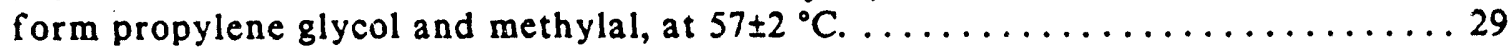

Figure 3-7. Gas chromatogram of the reaction mixture during the transacetalization

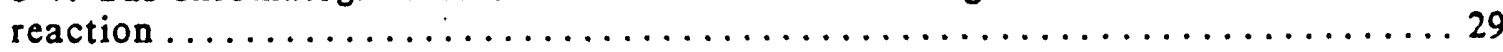

Figure 3-8. Kinetics of methylal hydrolysis reaction at $46 \pm 1{ }^{\circ} \mathrm{C} \ldots \ldots \ldots \ldots \ldots \ldots$

Figure 3-9. Kinetics of the reaction between 1,2-propanediol and acetaldehyde to form

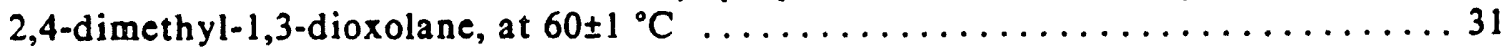

Figure 3-10. Aqueous- and toluene-phase concentrations of 1,2-propanediol and 2,4dimethyl-1,3-dioxolane during simultaneous reaction and extraction at $38^{\circ} \mathrm{C} \ldots 33$

Figure 3-11. Vapor-liquid equilibrium for 4-methyl-1,3-dioxolane and water, binary

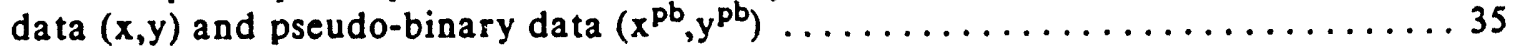

Figure 3-12. Vapor-liquid equilibrium data in the system 2,4-dimethyl-1,3-dioxolane and

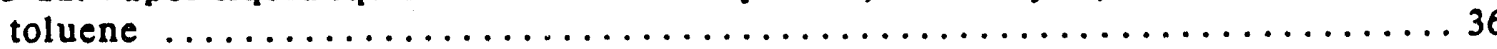




\section{List of tables}

Table 1-1. Some reactions of vicinal diols with aldehydes. $\ldots \ldots \ldots \ldots \ldots \ldots \ldots$

Table 3-1. Equilibrium constants for the reaction between propylene glycol and acetaldehyde. ................................. 24

Table 3-2. Reaction conditions for 4 md acetalization kinetics experiments. ...... 26

Table 3-3. Distribution ratios of $24 d$ md and acetaldehyde. $\ldots \ldots \ldots \ldots \ldots \ldots \ldots, \ldots \ldots$

Table 3-4. Composition (weight fractions) of equilibrium liquid phases in waterdioxolane systems. ................................. 34

Table 3-5. Liquid-liquid equilibrium data in the ternary system methanol (1) -

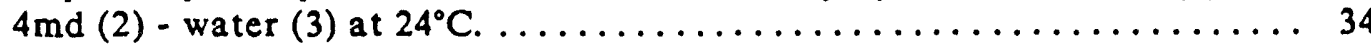


1. Introduction

\subsection{Recovery of hydroxylated compounds from aqueous solutions}

Recovery of compounds bearing multiple hydroxyl groups from aqueous solutions is important in many areas of the process industry. Recovery of fermentation chemicals from a complex and dilute broth, removal of these chemicals from waste streams generated by a variety of industrial processes and recovery of glycols from the aqueous solutions in which they are produced by petrochemical means are typical examples, each with their own set of complicating issues. They have one thing in common: the need to recover a chemical with low volatility and strongly hydrophilic characteristics from a dilute aqueous solution. This is a difficult separation problem, one that in many fermentation processes causes downstream processing to account for $40 \%$ or more of the final product cost.

The most straightforward approach is multiple-effect evaporation or distillation. All the water must be evaporated, but by using the multiple-eff ect approach the required heat load is reduced. However, even in a triple-effect evaporation system, the heat required per pound of recovered chemical is high and, to a first approximation, inversely proportional to the concentration of the aqueous solution. Also, the chemical of interest is of ten just one of many non-volatile chemicals in the solution; differentiation among these can be difficult and inefficient.

More economical separation methods are required, especially in cases where fermentation chemicals must compete with synthetically produced chemicals that have relatively low downstream processing costs. Such methods must capitalize on specific properties of the chemicals to be recovered, to remove them selectively and efficiently from solution.

Chemicals of interest include glycerol and diols (which have boiling points well above that of water) and saccharides (which are non-volatile). The research described in this thesis focuses mainly on propylene glycol (1,2-propanediol), which is a large-scale petrochemical product and potential fermentation chemical of commercial interest. Furthermore, its optical isomers (an $R$ - and an $S$ - form) do not differ in their physical properties. Another important fermentation glycol is 2,3-butanediol, which has a meso form with different properties than 
the $R$ - and $S$-forms. The study of a mixture of two chemicals which differ in such areas as reactivity and residence time on a chromatography column would be a complex task. The use of 1,2-propanediol avoids these complications.

Propylene glycol is used in the production of polyester resins. It also has applications in the food and pharmaceutical industries. Currently it is produced from propylene oxide in a high-temperature, high-pressure hydrolysis reaction. The molar ratio of water to propylene oxide must be high to minimize dipropylene glycol formation. A compromise between yield and purification costs leads to a ca. $15 \%$ aqueous solution of propylene glycol as the product stream (Wagner, 1978). The water is removed by multiple-effect evaporation.

A fermentation which produces $R$-propylene glycol from glucose, using the bacterium Clostridium thermosaccharolyticum, is described by Cameron and co-workers (Cameron and Cooney, 1986; Cameron et al., 1990). The concentration of propylene glycol in the product mix is about $0.8 \%$ by weight.

Other glycols which can be produced by fermentation include 1,3-propanediol (trimethylene glycol), using glycerol as a substrate (Cameron and Cooney, 1986), and various butylene glycols, e.g. 2,3-butylene glycol from glucose (Senkus, 1946a).

Chemical properties of glycols that may allow them to be selectively recovered include their hydrogen-bonding capability, their characteristics in Lewis acid-base interactions, their ability to form specific chemical complexes with certain compounds and their ability to participate in specific reversible chemical reactions. Avenues to capitalize on these properties include chemical extraction and adsorption with extractants and adsorbents of well-chosen functionalities, adductive crystallization and reversible selective chemical reaction, followed by separation and back-reaction.

\subsection{Reversible chemical reaction}

Glycols and related compounds are so difficult to recover from aqueous solution because of their hydrophilic properties. These in turn are caused by the presence of two or more hydroxyl groups, i.e. the ability to form multiple hydrogen-bonds with surrounding water molecules. The activity coefficient at infinite dilution for 1,2-propanediol in water is about 
1, compared to a value of ca. 20 for 1-propanol (Gmehling et al, 1981). A possible avenue towards easier recovery of glycols would therefore be to react them to form a chemical that does not have multiple hydroxyl groups or other highly polar groups, separate this chemical from the aqueous solution, and subsequently reverse the reaction to recover the glycol. Glycols participate in many of the same reactions that alcohols do, such as esterifications and etherifications (Curme, 1952). Reactions of this type reduce the hydroyen-bonding capability of the compound (especially if all available hydroxyl groups are reacted this way) but add molecular weight, so that the boiling point of the resulting chemical is still well above that of water and the volatility above an aqueous solution may not be high enough to allow an easy separation by distillation. One type of reaction, however, is specific to glycols. Diols with hydroxyl groups on neighboring carbon atoms (vicinal diols) or on carbons spaced two carbon atoms apart can be reacted with aldehydes to form five- or six-membered heterocyclic compounds, 1,3-dioxolanes and 1,3-dioxanes respectively, in a cyclic acetalization reaction. Depending on the specific glycol and aldehyde used, a variety of substituted dioxolanes can be formed:

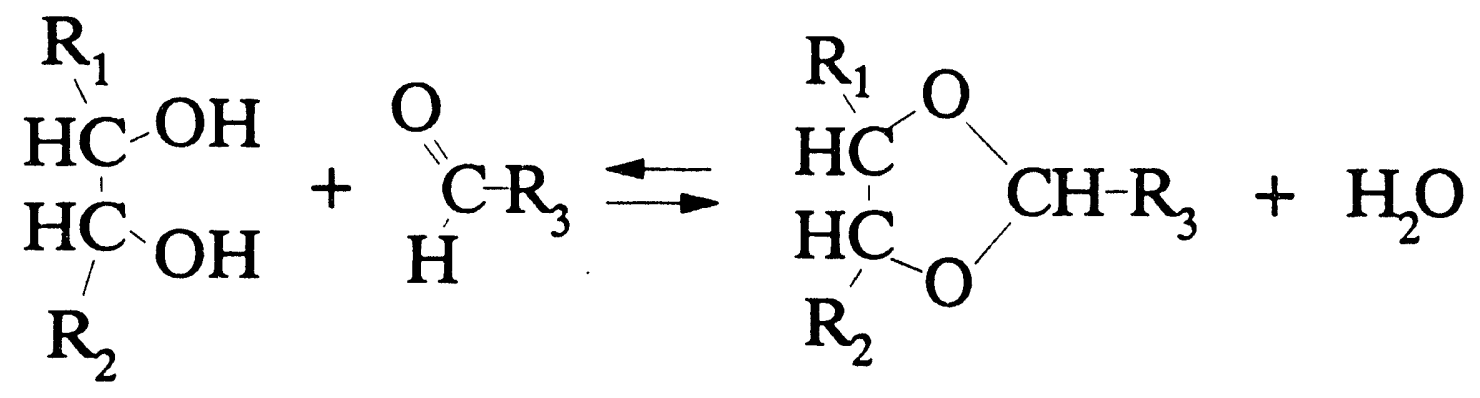

and

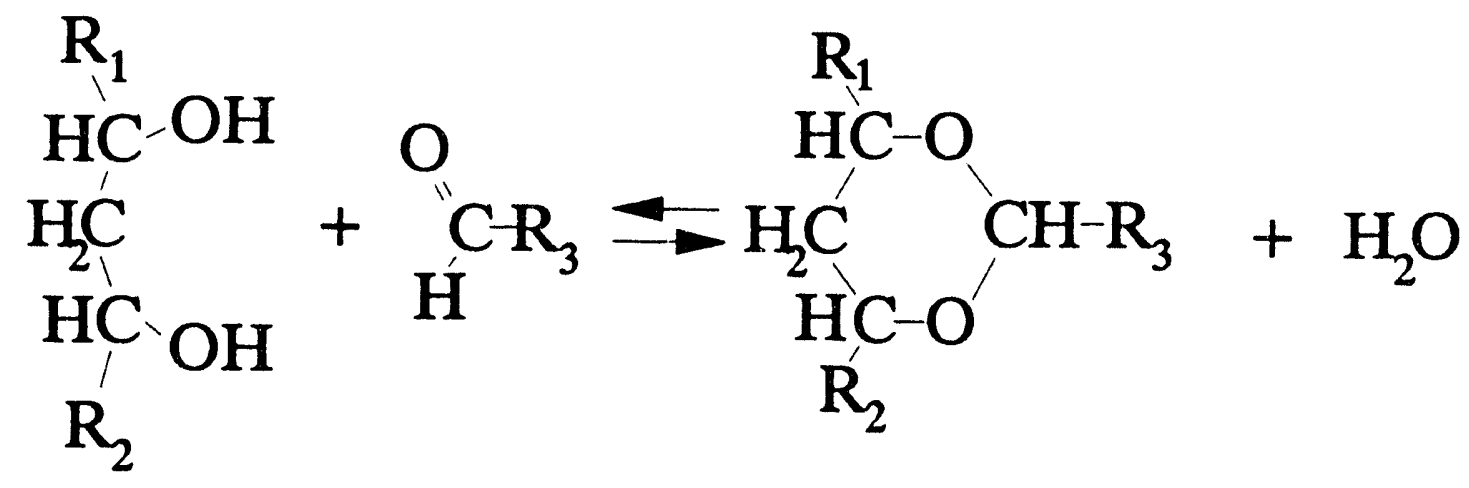


A few reactions of particular interest are listed in Table 1-1. However, reactions of this type are not limited to glycols. Tink and Neish (1951) reacted a variety of saccharides, sugar alcohols, glycols and glycerol with butyraldehyde. With the exception of several of the monosaccharides, all these compounds were converted to a considerable extent.

\begin{tabular}{|l|l|l|l||}
\hline \multicolumn{2}{|l|}{ Table 1-1. Some reactions of vicinal diols with aldehydes. } & Thb $\left.{ }^{\circ} \mathrm{C}\right)^{*}$ \\
\hline \hline glycol & aldehyde & dioxolane product & $75^{1}$ \\
\hline 1,2-ethanediol & formaldehyde & 1,3 -dioxolane & $84.2^{2}$ \\
\hline 1,2-propanediol & formaldehyde & 4-methyl-1,3-dioxolane & cis: $90.5^{3}$ \\
\hline 1,2-propanediol & acetaldehyde & 2,4-dimethyl-1,3-dioxolane & trans: $93.3^{3}$ \\
\hline 1,2-propanediol & propanal & 2-ethyl-4-methyl-1,3-dioxolane & cis \& trans: \\
\hline 2,3-butanediol & formaldehyde & 4,5 -dimethyl-1,3-dioxolane & cis: $97.0^{5}$ \\
& & & trans: $101.5^{5}$ \\
\hline
\end{tabular}

* Sources of boiling points are ${ }^{1}$ Astle et al. (1954), ${ }^{2}$ Lucas et al. (1950), ${ }^{3}$ Salomaa and Kankaanperä (1961), ${ }^{4}$ Willy et al. (1970), ${ }^{5}$ Senkus (1946).

\subsection{Literature overview}

Senkus $(1946 \mathrm{a}, \mathrm{b})$ used an acetalization to recover 2,3-butanediol from a fermentation broth containing $3.5 \%$ of the glycol by weight. The recovery was done in several batch reaction and separation steps. First ethanol, a by-product of the fermentation, was distilled out of the broth. Then an excess of formaldehyde was added, along with sulfuric acid as a catalyst. The reaction product, 4,5-dimethyl-1,3-dioxolane, was removed in its azeotrope with water by distillation, to force the reaction to completion. In a second reaction step, the dioxolane was reacted with methanol in a transacetalization, to recover the glycol and form methylal 
(dimethoxymethane, b.p. $41^{\circ} \mathrm{C}$ ), which was removed from the reaction mixture by distillation as it was formed. Excess formaldehyde was recovered from the broth by reacting it with methanol to form methylal. The methylal from both sources can be hydrolyzed to the original reactants, methanol and formaldehyde, which can be reused. All the reactions mentioned were catalyzed by strong mineral acids. The yields for the acetalization and transacetalization reactions were $99 \%$ and $94 \%$, respectively.

Lucas et al. (1950) prepared both ( \pm )-4-methyl-1,3-dioxolane and $R$-4-methyl-1,3dioxolane from propylene glycol and paraformaldehyde. They report that the conversion to the acetal is essentially quantitative. The acetal is recovered as the azeotrope with water (b.p. $74^{\circ} \mathrm{C}$ at $745 \mathrm{mmHg}$ ). The overall yield after drying was $95 \%$.

A series of studies (Tink and Neish, 1951; Tink et al., 1951; Tink and Roxburgh, 1951; Roxburgh, 1951) investigated the extraction of a variety of polyhydroxy compounds into an organic phase consisting of a carbonyl compound. The polyhydroxy compound was taken up into the organic phase as the corresponding cyclic acetal. $n$-Butyraldehyde was found to be the best extractant. Batch and continuous extraction of glycerol into $n$-butyraldehyde and the subsequent recovery of the aldehyde were studied experimentally. Recovery of glycerol was shown to be a strong function of the mineral acid concentration and the residence time in the liquid-liquid extraction device. The aldehyde was lost significantly in the process due to its solubility in water and side reactions under the influence of the acid catalyst.

Astle et al. (1954) carried out acetalization reactions under the influence of a strong acid ion exchange resin, Amberlite IR-120. This eliminates the need for the addition of a strong mineral acid as a catalyst. Conversion to the dioxolane in these experiments was high, and with proper recycling operations very high yields would be expected.

\subsection{Reactive distillation}

To a void the costs of purchase and subsequent removal/disposal of strong mineral acids, it is proposed to carry out the acetalization reaction and the subsequent hydrolysis reaction with a strong acid ion exchange resin as a solid catalyst.

For either of the distillative processes described in Section 1.7 to be feasible, the reaction conversion must be complete. Tink et al. (1951) quote an equilibrium constant for the 
reaction of $n$-butyraldehyde and glycerol: The ratio [water][acetal]/[glycerol][aldehyde] is ca. 170 at $30^{\circ} \mathrm{C}$ and $\mathrm{ca} .120$ at $40^{\circ} \mathrm{C}$. Noting that the concentration of water in dilute aqueous solution is about $55 \mathrm{~mol} / \mathrm{l}$, this denotes a far from complete equilibrium conversion. It is therefore necessary to force the reaction in the forward direction. This may be achieved through the application of reactive distillation, in which a product (in this case the dioxolane) is continuously removed from the reaction zone. This technique allows complete conversion of the glycol to the dioxolane.

In reactive distillation, a chemical reaction and multi-stage distillation are carried out simultaneously. Such an operation can have many advantages over separate reaction and separation operations (DeGarmo et al., 1992). In cases where the reaction equilibrium is unfavorable, it avoids large recycle streams, and the large equip!nent size associated with processing these streams. The heat of reaction causes vaporization in the distillation column rather than an increase in reactor temperature, which may obviate the need for temperature control equipment. Due to the possible use of reactive distillation as a means of obtaining methyl tertiary butyl ether (MTBE) from methanol and mixed butenes, this technology has seen an increased level of interest in recent years (e.g., Flato and Hof fmann, 1992).

Reaction takes place in a reaction zone; the limiting reactant is depleted in this zone, while the action of distillation causes reaction products and, when applicable, excess reactants, to be separated and purified in the rectification and stripping sections of the column.

For reactive distillation to be applicable, the reaction must proceed at a rate that is high enough to be compatible with a typical distillation column residence time. Therefore, a catalyst that is active and stable in the range of temperatures found in the reaction zone of the column must be available.

Reactive distillation may be implemented in different ways. Most early attempts used various ways of immobilizing pelletized catalyst onto traditional sieve plates in a distillation column, e.g. catalyst particles contained within cloth bags (Jones, 1984; Smith, 1984). Recent developments include the immobilization of catalyst material onto structured packings, allowing for more intimate contact between the liquid phase and the catalyst material (DeGarmo et al., 1992). 
To determine if reactive distillation is a viable technique for the reactions of interest in the processes described above, data on the reaction equilibrium, reaction kinetics (in both forward and reverse directions) and vapor/liquid equilibrium of dioxolane/water systems are needed. This is true also for the transacetalization and methylal hydrolysis reactions (in the formaldehyde case). There are some kinetic data published for the hydrolysis of dioxolanes (Aftalion et al., 1965; Salomaa and Kankaanperä, 1961) and the hydrolysis of methylal (Löbering and Fleischmann, 1937; McIntyre and Long, 1954; Koskikallio and Whalley, 1959), but these data are all for the reastion catalyzed by strong mineral acids. No data are available for the case where an ion exchange resin (or any other solid material) is used as a catalyst.

\subsection{Simultaneous reaction and extraction}

An alternative to reactive distillation as a means of forcing the acetalization reaction to equilibrium is the use of combined reaction and extraction. The aqueous phase containing dis:l, aldehyde and dioxolane would be countercurrently contacted with an organic solvent. The solvent would take advantage of the hydrophobic character of the dioxolane, leading to a large distribution ratio of the dioxolane between the organic and aqueous phases. At the same time, it should have a low distribution ratio for the aldehyde, which must react with the glycol in the aqueous phase. The reaction could be carried out in a continuous countercurrent contacting device, such as a rotating disc contactor, or alternatively in a series of mixersettlers, staged for overall countercurrent flow.

\subsection{Simultaneous reaction and adsorption}

If a regenerable adsorbent could be identified that exhibited a strong affinity and high capacity for dioxolanes, the reaction of a glycol with an aldehyde could be coupled with adsorption, analogous to the coupling with distillation and extraction described in previous sections. For an efficient process, the adsorbent would need to have superior uptake characteristics compared to uptake of the diols themselves. Adsorbents with inert surfaces, e.g. macroreticular styrene/divinylbenzene such as Amberlite XAD-2 and XAD-4, would be candidates. This a venue was not explored. 


\subsection{Proposed reactive separation processes}

It is now possible to envision various separation processes based on this type of reversible reaction. In the following, propylene glycol will be used as the glycol of interest. Formaldehyde and acetaldehyde will be considered for the aldehyde reactant. The reaction products are 4-methyl-1,3-dioxolane (4md) and 2,4-dimethyl-1,3-dioxolane (24dmd), respectively.

\subsection{1: The distillative formaldehyde process}

Figure 1-1 shows a flow schematic of the process using formaldehyde.

Formaldehyde is commercially available as an aqueous solution, at concentrations up to $40-50 \mathrm{wt} \%$. In some cases methanol is added as a stabilizer, to prevent polymerization of the formaldehyde. Formaldehyde solutions are complex mixtures of hydrates, hydrated oligomers

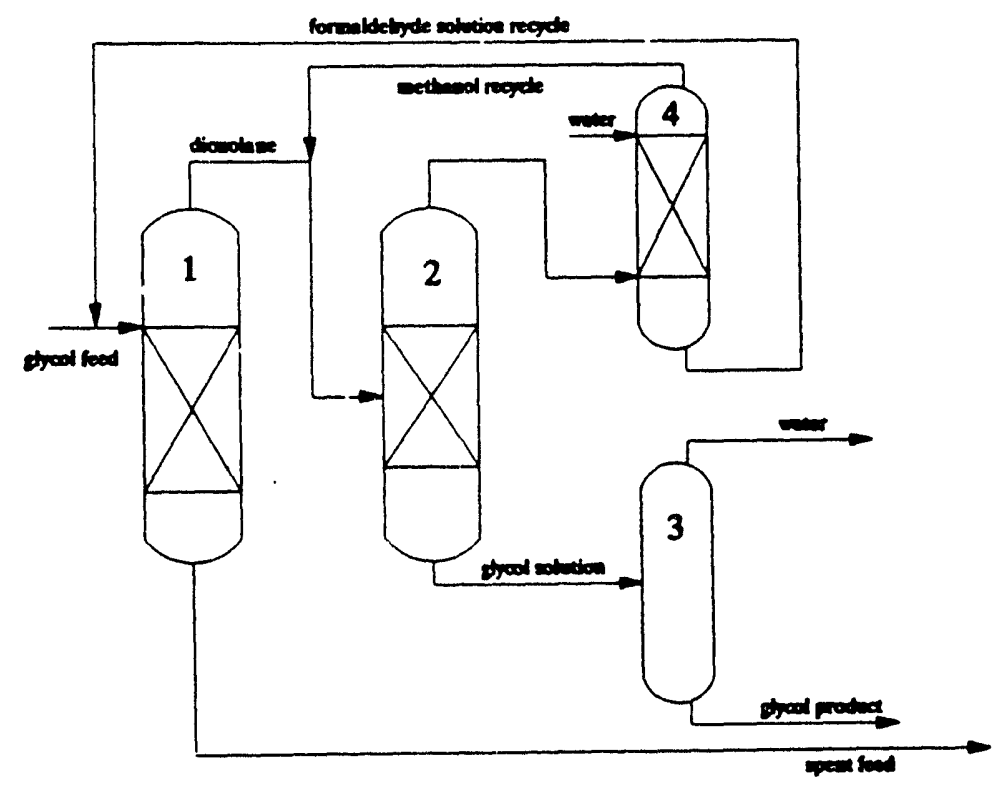

Figure 1-1. Flow schematic of the reactive distillation process with formaldehyde. (1) Acetalization column; (2) Transacetalization column; (3) Methylal hydrolysis column; (4) Glycol purification column.

and (when methanol is present) hemiacetals and hemiacetal oligomers. The concentration of free formaldehyde in such solutions is very low (Walker, 1975). The exact composition is a 
function of concentration and temperature; it can take days for the equilibrium composition to be reached when either of these parameters is changed.

The binary system of formaldehyde and water exhibits an unusual vapor/liquid equilibrium behavior (Gmehling et al., 1981). There is a minimum-boiling azeotrope at $1 \mathrm{~atm}$ and $97^{\circ} \mathrm{C}$ for a mol fraction of formaldehyde of 0.13 . At lower concentrations the volatility of formaldehyde relative to water is close to unity. Formaldehyde tends to polymerize out of the gas phase to form solid paraformaldehyde, $\mathrm{HO}\left(\mathrm{CH}_{2} \mathrm{O}\right)_{n} \mathrm{H}$. For these reasons it is impractical to take formaldehyde overhead in a distillation column.

A direct reversal of the acetalization reaction results in a mixture containing formaldehyde and propylene glycol which would be difficult to separate. Senkus (1946a) therefore added a transacetalization step, in which the dioxolane is reacted with methanol to form the glycol and methylal. In this case, methylal can be taken as the overhead and glycol as the bottoms product. When methylal is hydrolyzed in a subsequent reactive distillation column with an excess of water, a formaldehyde solution can be taken as the bottoms product and methanol as the distillate. Both streams can be recycled. If formaldehyde is used in excess, the spent broth must be treated to recover the excess amount.

\subsubsection{The distillative acetaldehyde process}

Figure 1-2 shows a flow schematic of the process using acetaldehyde.

Acetaldehyde, although similar to formaldehyde in chemical formula, has widely different properties. It is very volatile (b.p. $21^{\circ} \mathrm{C}$ ), does not form an azeotrope with water and does not readily polymerize. Under influence of a base, it undergoes aldol condensation to form aldol (3-hydroxy-butanal) anc heavier oligomers. In neutral and acidic solutions, however, acetaldehyde is stable. The consequences of the difference in properties are that acetaldehyde is much more volatile in aqueous solution and the process using acetaldehyde does not require a transacetalization step. The reaction products of a direct acetal hydrolysis are acetaldehyde and propylene glycol, which can be taken as distillate and bottoms product, respectively. An excess of acetaldehyde is necessary, since the aldehyde distributes unfavorably between the liquid and the vapor phase. A large vapor-phase concentration is 


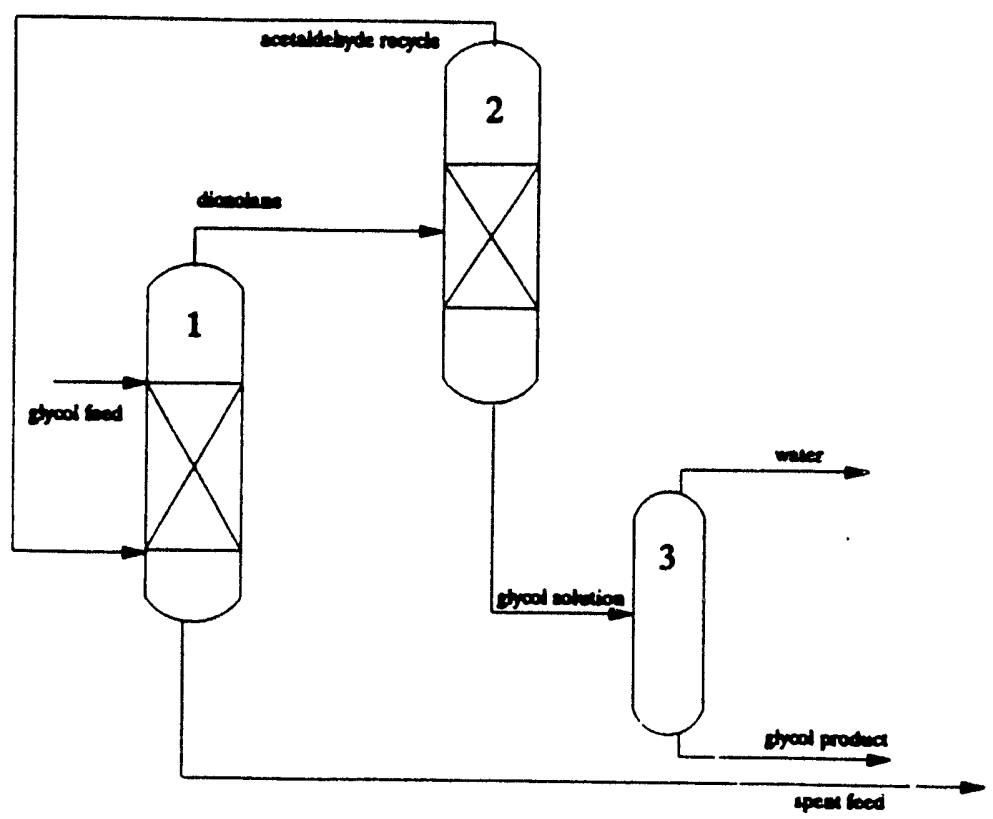

Figure 1-2. Flow schematic of the reactive distillation process with acetaldehyde. (1) Acetalization column; (2) Hydrolysis column; (3) Glycol purification column.

necessary to reach an appreciable liquid-phase concentration.

\subsubsection{The extractive acetaldehyde process}

A schematic flow diagram for a process using the reaction/extraction scheme described in Section 1.5 is presented in Figure 1-3. The extractor/reactor is shown as a continuous countercurrent contactor, but could be replaced by a series of mixer-settlers without consequences for the rest of the flow diagram. Processing downstream of the reactos/contactor includes stripping acetaldehyde out of both phases, distilling the dioxolane out of the organic phase and recovering the glycol from the dioxolane in a hydrolysis column. 


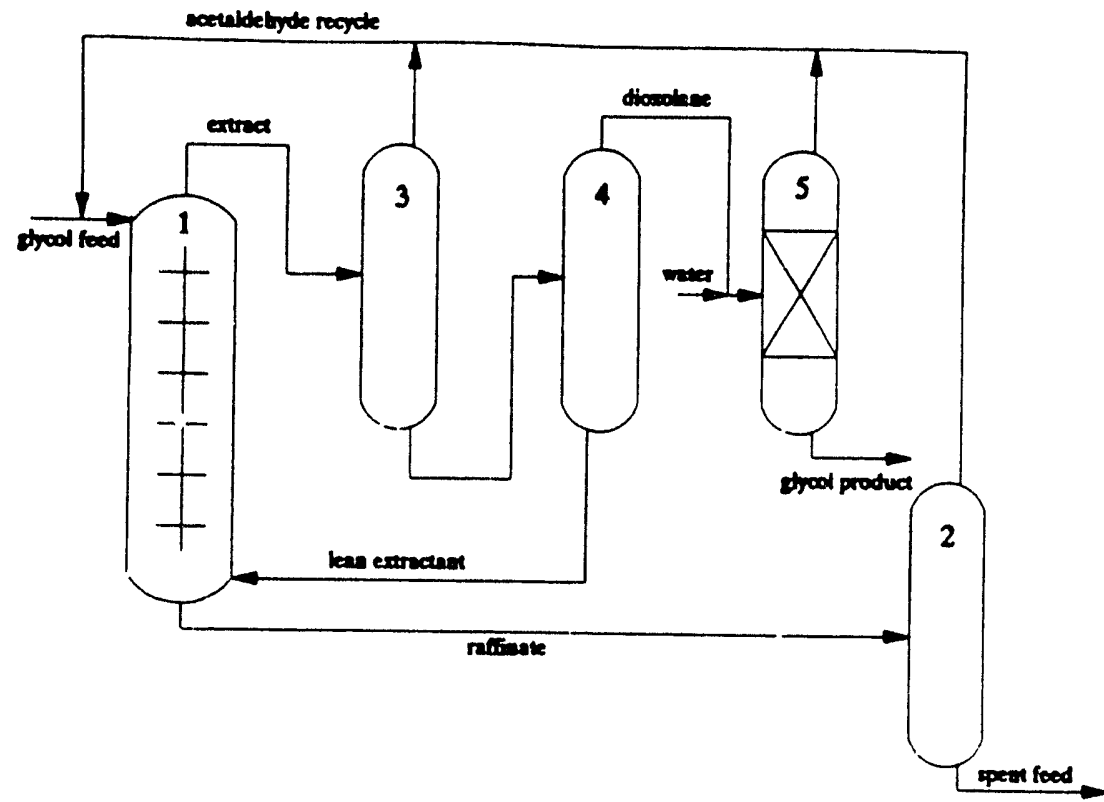

Figure 1-3. Flow schematic of the extractive acetaldehyde process. (1) Continuous countercurrent contactor/reactor; (2) and (3) Acetaldehyde stripping columns; (4) Dioxolane recovery column; (5) Hydrolysis column. 


\section{Experimental procedure}

Overviews of the chemicals and analytical techniques used in the experimental work are found in Appendices A and B, respectively.

\subsection{Ion exchange resins}

\section{Dowex 50W.}

Dowex $50 \mathrm{~W}$ is a strong-acid ion exchange resin in the hydrogen form, manufactured by Dow Chemical. The degree of crosslinking is $4 \%$, dry mesh size is $100-200$, and moisture content is $63 \%$. It was used as received in preparative and qualitative experiments.

\section{Amberlite IR-120 Plus (H).}

Amberlite IR-120 Plus (H) is a water-treatment resin, manufactured by Rohm \& Haas Co. It is a strongly acidic cation exchange styrene-divinylbenzene ( $8 \%$ crosslinking) resin, functionalized with sulfonic acid groups in the hydrogen ion form, containing 50-60 wt\% water. Bead size is $0.5 \mathrm{~mm}$. Manufacturer-specified exchange capacity is $1.9 \mathrm{meq} / \mathrm{ml}$ (wet). Drying and subsequent rehydrating caused fracture of the gel beads, so it was decided to use the resin as received.

\section{Amberlyst 15.}

Amberlyst 15 is a macro-reticular sulfonic-acid cation exchange resin, manufactured by Rohm \& Haas Co. It is designed to be used for catalytic purposes. It was obtained in wet form ( $52 \%$ moisture). Specifications include the capacity $(1.8 \mathrm{meq} / \mathrm{ml})$ and the surface area $(45$ $\mathrm{m}^{2} / \mathrm{g}$ ). The wet resin was used as received. 


\subsection{Preparation of various dioxolanes}

\section{4-Methyl-1.3-dioxolane (4md).}

The reaction was carried out in a $500-\mathrm{ml}$, round-bottom flask, equipped with $330-\mathrm{cm}$, 1-inch-diameter vacuum-jacketed column packed with 6-mm ceramic Berl saddles in a distillation setup. The reactants were added to this flask in equimolar amounts, $228 \mathrm{~g}$ propylene glycol $(3.0 \mathrm{~mol}$ ) and $243 \mathrm{~g}$ formaline ( $3.0 \mathrm{~mol}$ formaldehyde). Most of the methanol and methylal present in the formaline were distilled off before ca. $20 \mathrm{~g}$ of Dowex 50 was added as catalyst. In the subsequent batch reactive distillation, fractions rich in $4 \mathrm{md}$ were collected. Water, methanol and methylal were the main contaminants. Most of the condensate distilled at a vapor temperature of $c a .76^{\circ} \mathrm{C}$, which suggests that at that temperature the azeotropic mixture of $4 \mathrm{md}$ and water is collected. As the distillation proceeded, the water content of the distillate reached a level high enough to cause a phase split. The distillation was stopped when the distillate no longer split into two phases, i.e., when the dioxolane content of the distillate reached a value below its solubility in water.

The condensate fractions were combined and saturated with potassium chloride, to decrease the mutual solubility of $4 \mathrm{md}$ and water. The aqueous phase $(50 \mathrm{ml})$ and the organic phase $(230 \mathrm{ml})$ were separated. The $4 \mathrm{md}$ content of the former was analyzed by GC and found to be $15 \mathrm{wt} \%$. This phase was discarded. The latter was dried over molecular sieves.

A final distillation was carried out very slowly, to separate $4 \mathrm{md}$ from its main impurities, methanol and methylal. With the equipment available, separation was imperfect; only the distillation fractions containing $99.5+w t \% 4 \mathrm{md}$ were consolidated. The yield was ca. $110 \mathrm{~g} 4 \mathrm{md}(1.25 \mathrm{~mol})$, boiling at $84.5^{\circ} \mathrm{C}$.

\section{4-Dimethyl-1.3-dioxolane (24dmd)}

A mixture of $80 \mathrm{~g}$ propylene glycol (1.05 mol), $10 \mathrm{~g}$ Dowex 50 ion exchange resin and $5 \mathrm{~g}$ potassium chloride was stirred in a $250-\mathrm{ml}$ round-bottom flask immersed in an ice bath. Sixty $\mathrm{ml}$ acetaldehyde $(1.06 \mathrm{~mol})$ was slowly added to this mixture, with an attempt made to avoid boiling as the exothermic reaction proceeded. After the addition was completed, the flask was stoppered and stirring was continued for $10 \mathrm{~min}$ in the ice bath, and then for half 
an hour at room temperature. The potassium chloride and Dowex 50 were removed by filtration, resulting in two clear liquid layers -- a top clear organic la yer, consisting mainly of $24 \mathrm{dmd}$, and a bottom orange aqueous layer, containing unreacted propylene glycol and acetaldehyde, some $24 \mathrm{dmd}$, and unidentified heavier organic compounds.

The top phase, which contained 2 wt\% water, was dried over molecular sieves. The reaction of $24 \mathrm{dmd}$ with water (the reverse of its formation) proceeds at a considerable rate at higher temperatures, even when not catalyzed, so that the removal of water before final distillation was essential.

Acetaldehyde was distilled of $f$ in an easy final separation, to produce more than $100 \mathrm{~g}$ $24 \mathrm{dmd}$ (ca. $0.98 \mathrm{~mol}$ ) with a purity of $99.5+\%$. The boiling point of the product was $93.0^{\circ} \mathrm{C}$. The main impurities were acetaldehyde, propylene glycol and an unidentified heavier compound. Analysis with GC/MS (as described in Appendix B) shows that both the cis-and the trans-isomer are formed; the quantitative analysis on the Varian 3700 did not distinguish between the isomers.

\section{2-Ethyl-4-methyl-1,3-dioxolane (2e4md)}

Propanal was reacted with propylene glycol in approximately equimolar quantities, with Dowex 50 as a catalyst. Two isomeric reaction products are expected, a cis-and a trans-isomer. The reaction mixture was analyzed using the GC/MS technique described in Appendix B. Besides the expected products, many byproducts were formed, the most prominent of which were aldol condensation products (hydroxy-aldehydes) and the corresponding dehydrated compounds (unsaturated conjugated aldehydes). Distillation of the complex mixture was not attempted. 


\subsection{Phase equilibrium measurements}

\section{Liquid-liquid equilibria}

Binary systems containing water and either $4 \mathrm{md}$ or $24 \mathrm{dmd}$ are not miscible in all proportions. Liquid-liquid equilibrium experiments were carried out, in which the compositions of both the aqueous and the organic phases were measured as a function of temperature, by gas chromatography and Karl Fischer titration, respectively. For both binary systems, the upper consolute temperature (the highest temperature at which two phases co-exist) is well above the atmospheric bubble point of the system, so that a miscibility envelope for the system could not be charted completely.

The addition of methanol serves to homogenize these binary heterogeneous systems. Liquid-liquid equilibrium measurements at atmospheric pressure and room temperature $\left(25^{\circ} \mathrm{C}\right)$ were carried out to obtain ternary equilibrium data for the system methanol/4md/water. The methanol contents of both phases and the $4 \mathrm{md}$ content of the aqueous phase were quantified using gas chromatography. The water content of the organic phase was quantified using Karl Fischer titration.

\section{Vapor-liquid equilibria}

A modified Othmer still was designed to carry out VLE measurements for the $4 \mathrm{md} /$ water, $24 \mathrm{dmd} /$ water and $24 \mathrm{dmd} /$ toluene systems. The still, shown in Figure $2-1$, consisted of a round-bottom flask which is heated by a spherical heating mantle and magnetically stirred, a water-cooled condenser and a vapor condensate return line with a condensate holdup loop. The section of the still between the flask and the condenser was heated with heating tape and insulated with glass wool. Thermometers were installed to monitor the temperature of the liquid inside the flask and the vapor just before entering the condenser. Samples of the liquid phase in the flask and the vapor condensate in the return loop were taken through septa. Care was taken to ensure that the vapor entering the condenser was slightly superheated, to avoid partial condensation before the condenser. The still was operated at atmospheric pressure.

The vapor-and liquid-phase samples were analyzed by gas chromatography. In cases where the water content of the system was low, Karl Fischer titration was used instead of, or 


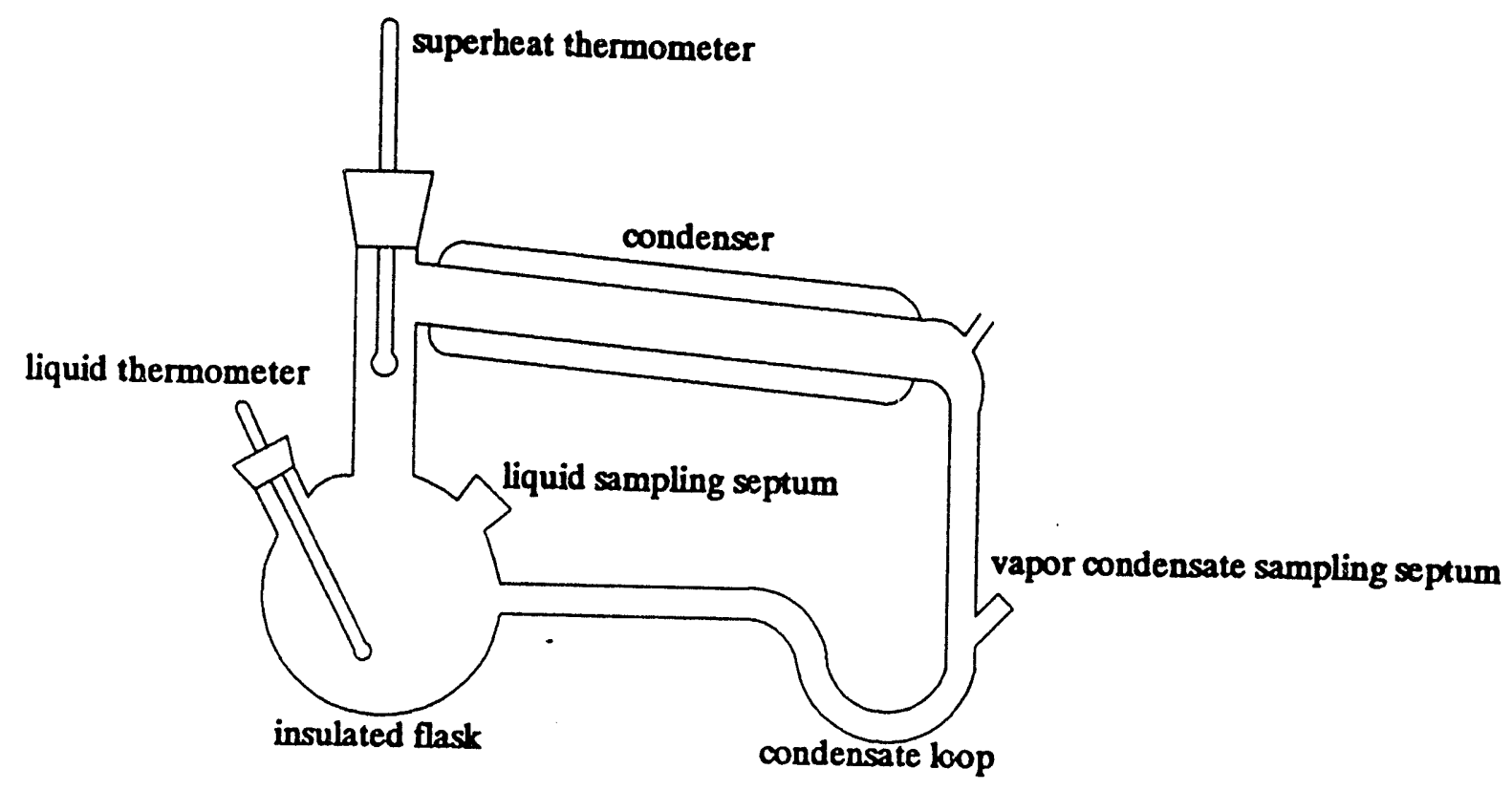

Figure 2-1. Diagram of the Othmer still used for VLE measurements.

in addition to, gas chromatography.

Some equilibrium points for the ethanol/water system were measured to ensure that the Othmer still produced true VLE data. Initially the data showed deviations from literature data, but after additional insulation was added and when the vapor condensate was analyzed by the Karl Fischer method, the measurements accurately corresponded with the data from the literature (see Figure 2-2)

For the system 4md/water, binary VLE data were collected in those composition regions where both the liquid phase and the vapor condensate phase were outside the region of immiscibility. Since this excludes a large composition region, additional experiments were carried out with methanol as a third component, to homogenize either or both phases. The methanol content of the system was kept as low as possible, to allow for interpretation of the ternary data as pseudo-binary data.

For the system $24 \mathrm{dmd} /$ water, just two VLE data points at low concentration of $24 \mathrm{dmd}$ were measured. The $24 d m d$ contents of both phases were measured by gas chromatography. At elevated temperatures, the uncatalyzed reaction between $24 \mathrm{dmd}$ and water proceeds at a 


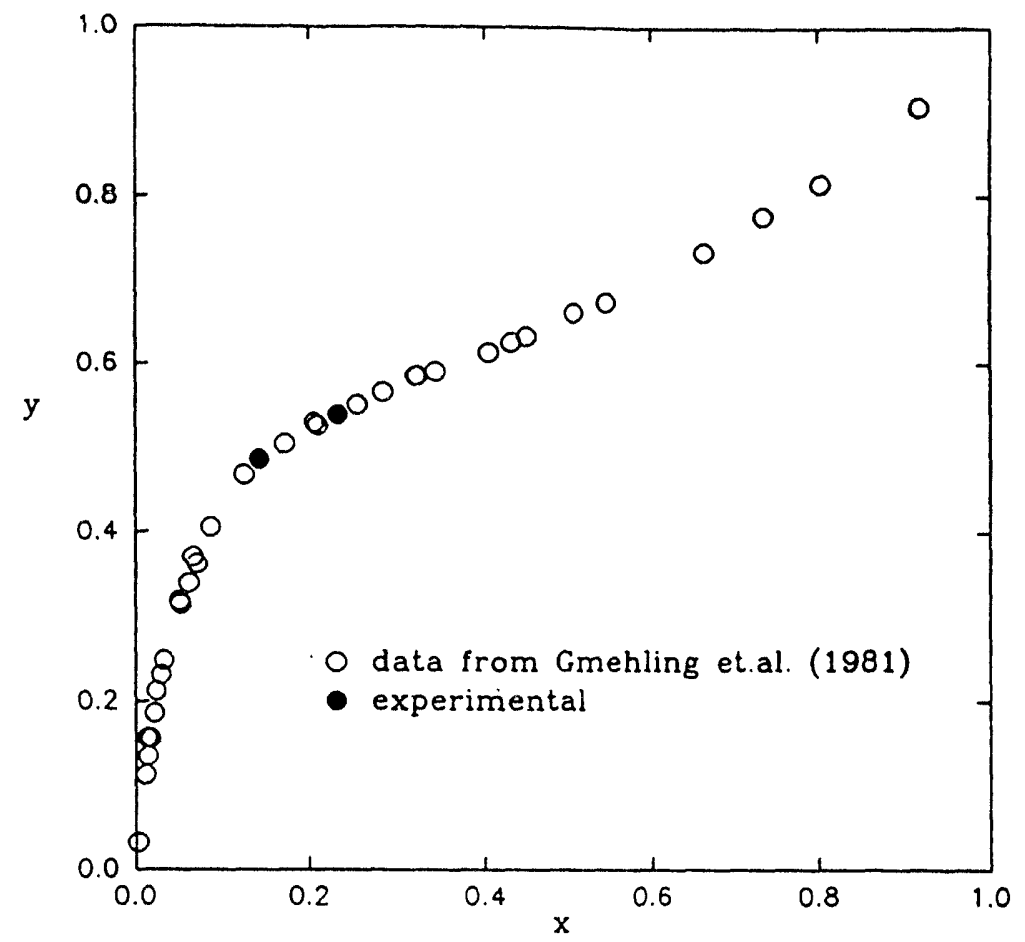

Figure 2-2. Comparison of two VLE measurements in the ethanol/water system with data from Gmehling et al. (1981).

considerable rate, making the task of measuring binary equilibrium data a difficult one.

A series of VLE data points for systems of $24 \mathrm{dmd}$ in toluene was measured. The concentrations of $24 \mathrm{dmd}$ in both phases were measured by gas chromatography, using binary $24 \mathrm{dmd} /$ toluene mixtures as standards.

\section{Extraction equilibria}

A number of solvents were screened for their utility as solvents to extract $24 \mathrm{dmd}$ from an aqueous phase. Dilute aqueous solutions of $24 \mathrm{dmd}$ were contacted with the solvent by stirring vigorously at room temperature in a $20-\mathrm{ml}$ scintillation vial. The $24 \mathrm{dmd}$ contents of both phases were then determined by gas chromatography. Subsequently, acetaldehyde was added to the system. After equilibrium had once again been reached, the concentrations of both acetaldehyde and $24 \mathrm{dmd}$ in both phases were measured. 


\subsection{Reactive distillation}

Batch experiments were carried out to investigate the feasibility of reacting propylene glycol with formaldehyde and simultaneously removing the product 4 md from the reaction mixture. Also, the transacetalization reaction with methanol to form methylal and propylene glycol was studied.

\section{Catalysis by strong mineral acids}

A mixture of $7.6 \mathrm{~g}$ propylene glycol $(0.1 \mathrm{~mol}), 10 \mathrm{~g}$ concentrated sulf uric acid and $16.7 \mathrm{~g}$ formaline ( $0.2 \mathrm{~mol}$ formaldehyde) in an aqueous sciution of $300 \mathrm{~g}$ total weight was heated in a 500-ml round-bottom flask equipped with a $15-\mathrm{cm}$ Vigreux column and a distillation/condenser setup. Most condensate was collected at a vapor temperature of $76-77^{\circ} \mathrm{C}$. The condensate was collected slowly, to allow the rate of reaction to keep up with the rate of distillation. The collection of distillate was stopped when the vapor temperature started rising and the incremental condensate was mainly water. The remaining reaction mixture was analyzed by GC.

The $8 \mathrm{ml}$ of condensate was combined with $5.0 \mathrm{~g}(0.16 \mathrm{~mol})$ of methanol, $4 \mathrm{~g}$ of water and $2 \mathrm{~g}$ of concentrated hydrochloric acid (36.5\%). This mixture was distilled slowly, until no more methanol or methylal condensed and the flask residue appeared viscous. The residue was neutralized with a sodium hydroxide solution, then analyzed by GC.

\section{Catalysis by ion exchange resin}

A number of experiments similar to those described in the section above were carried out, using Amberlite IR-120 ion exchange resin as a catalyst. Formaldehyde was used in ca. $100 \%$ excess. The catalyst concentration was ca. $6 \mathrm{~g} / 300 \mathrm{~g}$ solution. Distillation was allowed to proceed slowly. A large portion of the distillate was collected at a vapor temperature of 75 $76^{\circ} \mathrm{C}$. The degree of conversion was determined from the concentration of propylene glycol remaining in solution af ter the end of the reactive distillation. Conversions were around $60 \%$. Distillation was usually stopped when the vapor temperature reached $95-97^{\circ} \mathrm{C}$, at which temperature formaldehyde is expected to distill over in its azeotrope with water. This limited 
the recovery of propylene glycol as $4 \mathrm{md}$. Note that at the higher vapor temperatures, the water content of the distillate was high; the concentration of $4 \mathrm{md}$ in all of the distillate ranged from 40 to $60 \%$.

Methanol was added to the distillate in ca. $100 \%$ excess, along with ca. $6 \mathrm{~g}$ Amberlite IR-120. These mixtures were distilled at a low rate of distillate collection (distillations lasted several hours) and the residues were analyzed for propylene glycol by GC.

It is not possible to demonstrate the feasibility of the simultaneous hydrolysis of methylal and distillation of the products formed in a batch reactive distillation experiment, since the reactant methylal is more volatile than both of the products, methanol and aqueous formaldehyde.

Similarly, batch reactive distillation of $24 \mathrm{dmd}$ from propylene glycol and acetaldehyde is not possible, since the reactant acetaldehyde distills off before the product $24 \mathrm{dmd}$. For the same reason, $2 \mathrm{e} 4 \mathrm{md}$ cannot be prepared from propylene glycol and propanal by batch reactive distillation.

\subsection{Chemical equilibrium measurements}

The equilibria for the three reaction steps in the $4 \mathrm{md}$ process (acetalization, transacetalization and methylal hydrolysis) were studied at various temperatures. Measured amounts of the reactants were added to $20-\mathrm{ml}$ scintillation vials, along with IR-120 catalyst. When possible, the equilibrium was approached from both directions. The vials were put into a shaker bath until the composition no longer changed. Shaker bath temperatures were set at various values in the range $25-75^{\circ} \mathrm{C}$. The concentrations of reactants and products were then determined by gas chromatography, except for formaldehyde which was determined by the sulfite titration method, described in Appendix B. In a few cases, especially for the transacetalization reaction, a number of by-products were formed. Identification of these compounds was attempted using mass spectrometry. Mass spectra of the by-products were obtained by the GC/MS technique described in Appendix B. None of the spectra could be found in an extensive tabulation of mass spectra (ref). The prominent peaks appearing in the spectra are all at $\mathrm{m} / \mathrm{z}$ ratios commonly encountered in a variety of organic chemicals. To 
identif $y$ the by-products positively by other methods (e.g., inf ra-red spectrophotometry or NMR spectrometry) it would be necessary to obtain them in a concentrated form. Separation out of a complex dilute reaction solution would be difficult and was not attempted.

\subsection{Chemical kinetics measurements}

Glassware equipment was set up for the measurement of chemical kinetics of the acetalization, transacetalization and methylal hydrolysis reactions in the $4 \mathrm{md}$ process, and the acetalization reaction in the $24 \mathrm{dmd}$ process. A $250-\mathrm{ml}$ three-neck, round-bottom flask was equipped with a thermometer, a sampling tube with stopcock and an adapter to a pipet bulb. The reaction flask was stirred magnetically with an oval stirbar and heated by submersion in a temperature-controlled ethylene glycol bath. Reactants were weighed into the flask, after which the contents were brought up to reaction temperature. Reaction was initiated by the addition of a measured amount of Amberlite IR-120 or Amberlyst 15 ion-exchange resin. Samples were taken regularly through the sampling tube. The tube was flushed, and then a sample of ca. $1 \mathrm{ml}$ was taken for subsequent analysis. If the vapor pressure inside the flask did not exceed atmospheric pressure, the sample was forced out by applying pressure through the pipet bulb. Reaction temperatures ranged from $40^{\circ}$ to $100^{\circ} \mathrm{C}$.

Samples were analyzed by GC for a compound from which the reaction conversion could be calculated: $4 \mathrm{md}$ or $24 \mathrm{dmd}$ for the acetalizations, propylene glycol for the transacetalization and methanol for the methylal hydrolysis.

In the case of the acetalization to $24 \mathrm{dmd}$, the final reaction mixture was analyzed for acetaldehyde, propylene glycol and $24 \mathrm{dmd}$ by GC (water content follows by difference) to obtain values for the equilibrium constant at various temperatures. 
2.7. Simultaneous reaction and extraction experiment

Equal volumes $(50 \mathrm{ml})$ of a toluene phase and an aqueous phase containing $2 \mathrm{wt} \%$ propylene glycol and $20 \mathrm{wt} \%$ acetaldehyde were stirred vigorously in the equipment for kinetics measurements, described in the previous section. The result of the agitation was a fine dispersion with a high interfacial area for mass transfer. The temperature was maintained at $47^{\circ} \mathrm{C}$. Reaction was started by the addition $5 \mathrm{~g}$ of Amberlite IR-120. Samples of the two-phase mixture were taken regularly. After the phases had settled out in the sample vial, both phases were analyzed by GC, for $24 \mathrm{dmd}$ (both phases) and propylene glycol (aqueous phase only). 


\section{Results}

\subsection{Reactive distillation}

In various experiments it was shown that propylene glycol can be recovered from dilute aqueous solution by reaction with formaldehyde to $4 \mathrm{md}$. Reaction is promoted by strong mineral acids in solution as well as by strong acid ion exchange resins.

In the homogeneous catalysis experiment the reaction mixture at the end of the distillation still contained $16 \%$ of the original propylene glycol, as well as some $4 \mathrm{md}$. The amount of propylene glycol recovered by the subsequent methanolysis step corresponds to a combined yield for both reaction steps of $83 \%$.

The degrees of conversion in distillative acetalization catalyzed by Amberlite IR-120 were around $60 \%$. The $4 \mathrm{md}$ content of the total distillate collected ranged from $40-60 \%$. Since at the higher vapor temperatures at the end of the distillation the incremental distillate is predominantly water, this concentration depends on the temperature at which the distillation is stopped. The product of transacetalization reactions with methanol were ca. $30 \%$ propylene glycol solutions, corresponding to an overall glycol recovery of up to $50 \%$.

An excess of formaldehyde is necessary to achieve high conversion. Yields of $4 \mathrm{md}$ were as high as $97 \%$ when a sufficient excess of formaldehyde was used. When the yields were lower, they could be attributed to an experimental procedure in which quantities were distilled that were small relative to the.liquid holdup in the packed column, so that complete and efficient distillation was not possible.

The total volume of bottoms product was so low that the flask tended to overheat, resulting in decomposition reactions and the formation of unwanted by-products. In a continuous distillation this problem should not occur. 


\subsection{Chemical equilibrium}

Equilibrium of the acetalization reaction between propylene glycol and formaldehyde was reached in aqueous solution. The equilibrium constant $K$ (Equation 3-1) was calculated

$$
K=\frac{[4-\text { methyl-1,3-dioxolane }] \cdot[\text { water }]}{[\text { total formaldehyde }] \cdot[\text { propylene glycol] }}
$$

from the equilibrium concentrations at various temperatures. All calculated values were in the range 5.9-8.7; they are shown in Figure 3-1. The scatter in these values is too large for any

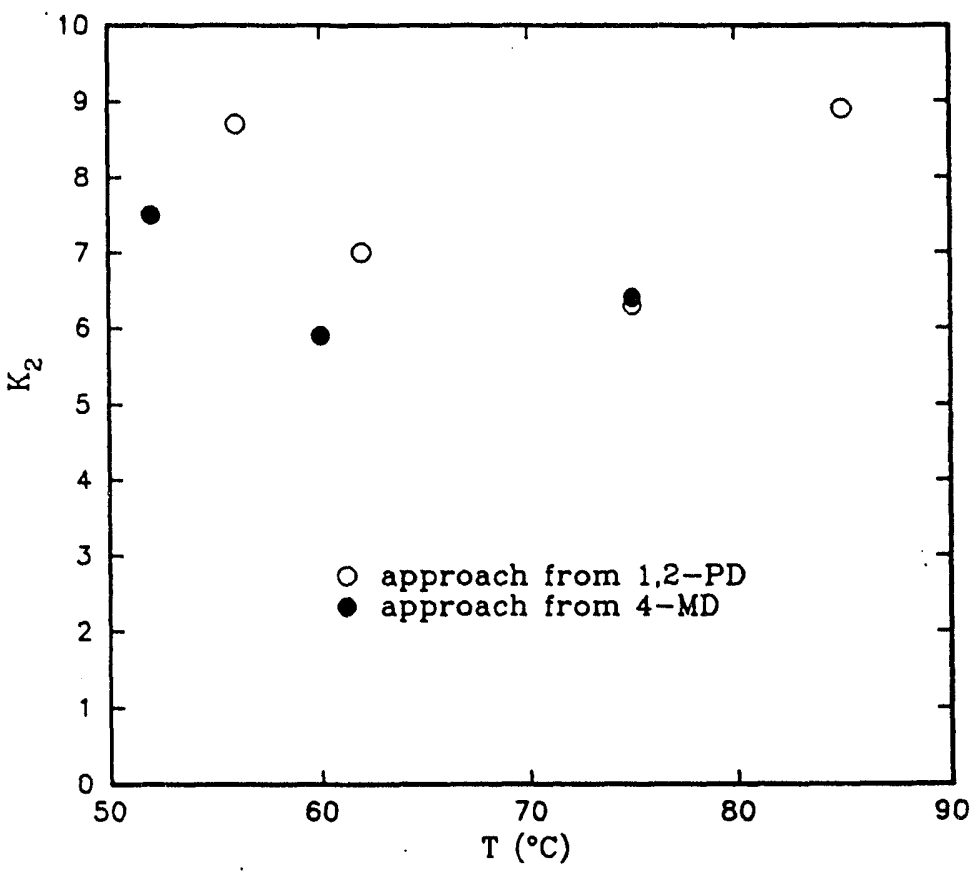

Figure 3-1. Equilibrium constants for the formation of 4-methyl-1,3-dioxolane from 1,2propanediol and formaldehyde, vs. temperature.

conclusions to be drawn concerning the temperature dependence of the reaction equilibrium. The reason for the scatter in the data may be that the concentration of free formaldehyde in solution is a function of the total concentration of formaldehyde species, as well as the concentrations of methanol and water, and is a very small fraction of the total formaldehyde concentration measured by the sulfite method. The assumption, explicit in Equation 4-1, that the equilibrium constant varies with the first power of the total formaldehyde concentration may be incorrect. 
The equilibrium constant for the reaction between propylene glycol and acetaldehyde are given in Table 3-1. The values were calculated from concentration measurements of the final reaction mixture in equilibrium experiments and in the kinetics experiment, over a range of temperatures.

\begin{tabular}{l}
\hline \begin{tabular}{|} 
Table 3-1. Equilibrium constants for the \\
reaction between propylene glycol and \\
acetaldehyde. \\
\hline $\mathrm{T}\left({ }^{\circ} \mathrm{C}\right)$ & $\mathrm{K}_{24 \mathrm{dmd}}$ \\
\hline 25 & 18.1 \\
\hline 40 & 17.1 \\
\hline 60 & 13.8 \\
\hline 83 & 8.5 \\
\hline
\end{tabular}
\end{tabular}

A plot of $\ln \left(\mathrm{K}_{24 \mathrm{dmd}}\right)$ vs. $1 / \mathrm{T}$ is a curve rather than a straight line (Figure 3-2), so that a heat of reaction cannot be unambiguously calculated from the data. Calculated from the average slope of the plot, the heat of reaction is $-11.5 \mathrm{~kJ} / \mathrm{mol}$.

Due to the difficulty of accurately analyzing methylal in aqueous solutions, no quantitative results were obtained for equilibria in the transacetalization and methylal hydrolysis reactions.

\subsection{Chemical kinetics}

Figure 3-3 shows plots of the conversion of propylene glycol to $4 \mathrm{md}$ as a function of time, for various temperatures and initial concentrations. In these experiments Amberlite IR120 was used as a catalyst. Table 3-2 lists the exact conditions of each of the Amberlite IR-120 experiments. In experiments at higher temperatures smaller amounts of catalyst were used to 


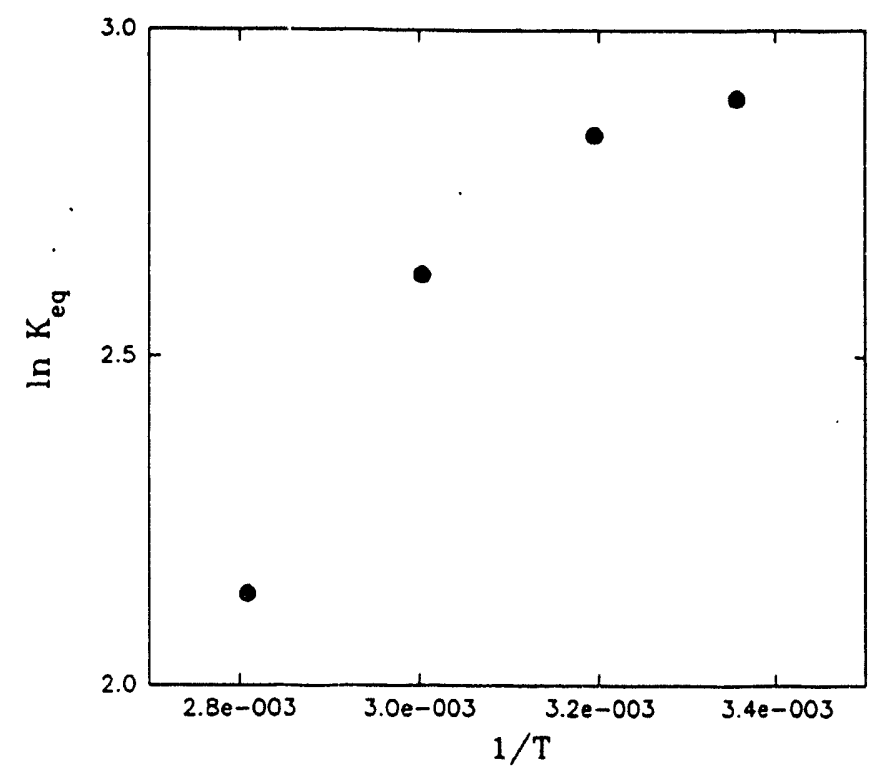

Figure 3-2. Equilibrium constants for the formation of 2,4-dimethyl-1,3-dioxolane from 1,2propanediol and acetaldehyde, vs. temperature.

ensure the reaction time scale was of the same order of magnitude as the sampling time scale. For this reason, the time coordinate in Figure 3-3 is normalized by multiplying by the weight ratio of catalyst to solution. 


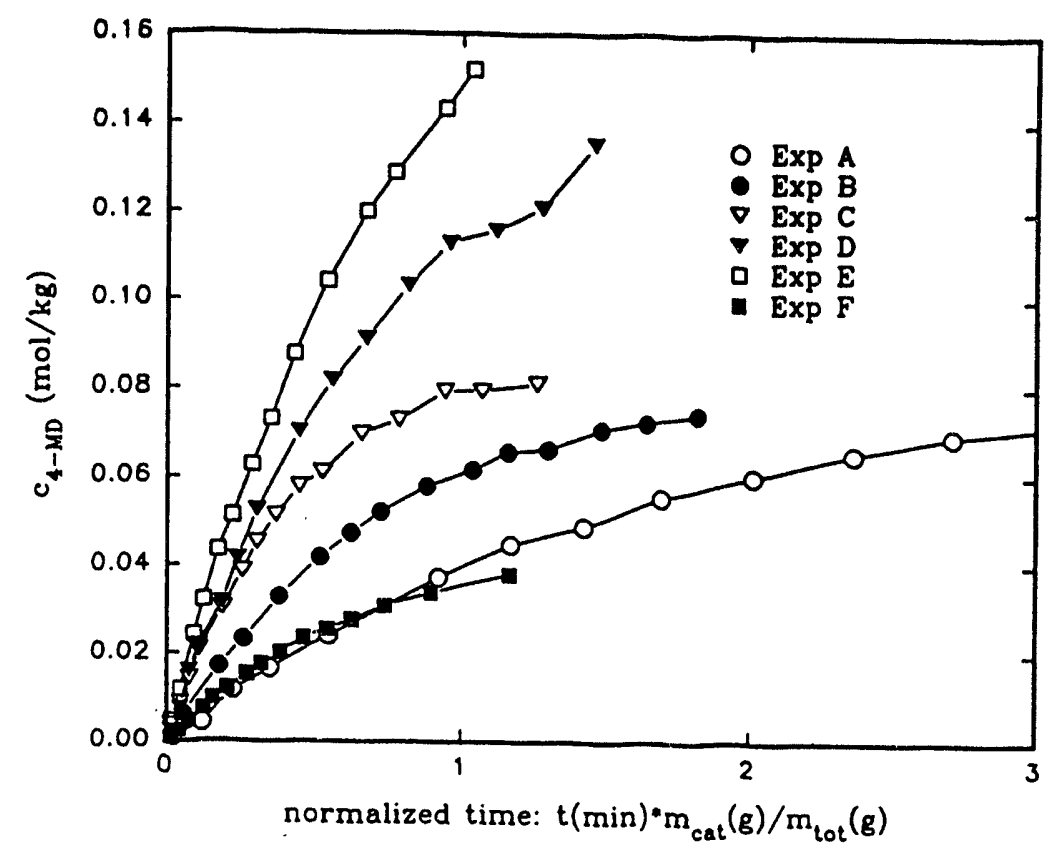

Figure 3-3. Kinetics of the reaction between 1,2-propanediol and formaldehyde to form 4methyl-1,3-dioxolane. Table 3-2 lists reaction conditions.

\begin{tabular}{||l|l|l|l|l|l||}
\hline \multicolumn{6}{|c|}{ Table 3-2. Reaction conditions for 4md acetalization kiretics experiments. } \\
\hline \hline Exp & $\begin{array}{l}\text { Temp. } \\
\left({ }^{\circ} \mathrm{C}\right)\end{array}$ & $\begin{array}{l}\text { [glycol] } \\
(\mathrm{mol} / \mathrm{kg})\end{array}$ & $\begin{array}{l}{[\mathrm{HCHO}]} \\
(\mathrm{mol} / \mathrm{kg})\end{array}$ & $\begin{array}{l}\text { IR-120 } \\
(\mathrm{w} / \mathrm{w})\end{array}$ & $\begin{array}{l}\mathrm{r}_{0} \\
\left(\mathrm{~mol} / \mathrm{kg}_{\mathrm{cat}} \mathrm{min}\right)\end{array}$ \\
\hline A & 80 & 0.788 & 0.781 & 0.0248 & 0.034 \\
\hline B & 90 & 0.782 & 0.783 & 0.0200 & 0.095 \\
\hline C & 98.5 & 0.778 & 0.782 & 0.0160 & 0.190 \\
\hline D & 90 & 0.781 & 1.560 & 0.0160 & 0.202 \\
\hline E & 90 & 1.586 & 0.903 & 0.0159 & 0.253 \\
\hline F & 90 & 0.390 & 0.798 & 0.0160 & 0.061 \\
\hline G & 92 & 0.382 & 0.382 & 0.100 & 0.027 \\
\hline
\end{tabular}

Included in Table 3-2 is the initial rate, $r_{0}$, for each of these experiments, as determined from the initial slopes of the curves in Figure 3-3. The hypothesis that the reaction is first order in each of the reactants was tested by plotting the initial rate $r_{0}$ of the experiments 
carried out at $90^{\circ} \mathrm{C}$ vs. the product of the glycol and formaldehyde concentrations. This plot, shown in Figure 3-4, follows a straight line, which supports the reaction order hypothesis. In

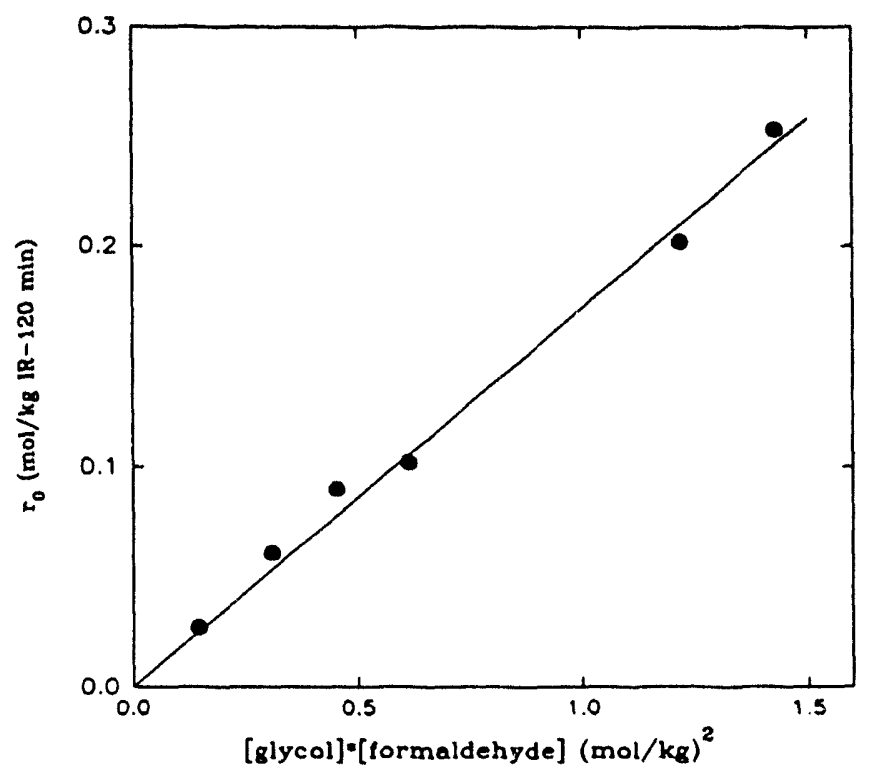

Figure 3-4. Initial reaction rate vs. the product of initial reactant concentrations.

Figure 3-5, $\ln r_{0}$ is plotted $v s .1 / T$. From the slope of this Arrhenius plot the activation energy for the reaction can be calculated to be $101 \mathrm{~kJ} / \mathrm{mol}$.

More rigorously, the dependence on each of the four variables influencing the reaction rate (the weight ratio of catalyst to solution $w_{\text {cat, }}$, the concentrations of formaldehyde and propylene glycol and the temperature) can be found by linear regression of all of the results given in Table 3-2. The exponents on the first three variables are found to be $0.91 \pm 0.20$, $0.90 \pm 0.17$ and $1.01 \pm 0.31$, respectively, which is further support for the first-order dependence on each of these variables. The activation energy calculated by the regression analysis is $\mathbf{1 0 1 . 6}$ $\mathrm{kJ} / \mathrm{mol}$. The expression correlating the reaction rates of all the experiments described above is then given in Equation 3-2, in which $r$ is the rate in $\mathrm{mol} / \mathrm{kg} \mathrm{min}$, $\mathrm{w}_{\text {eat }}$ is in $\mathrm{kg}$ cat/ $\mathrm{kg}$ solution

$$
r=4.73 \cdot 10^{13} \cdot w_{\text {cat }} \cdot[g l y c o l][H C H O] \cdot e^{-101600 / R T}
$$

and the concentrations of propylene glycol and formaldehyde are given in mol/kg. 


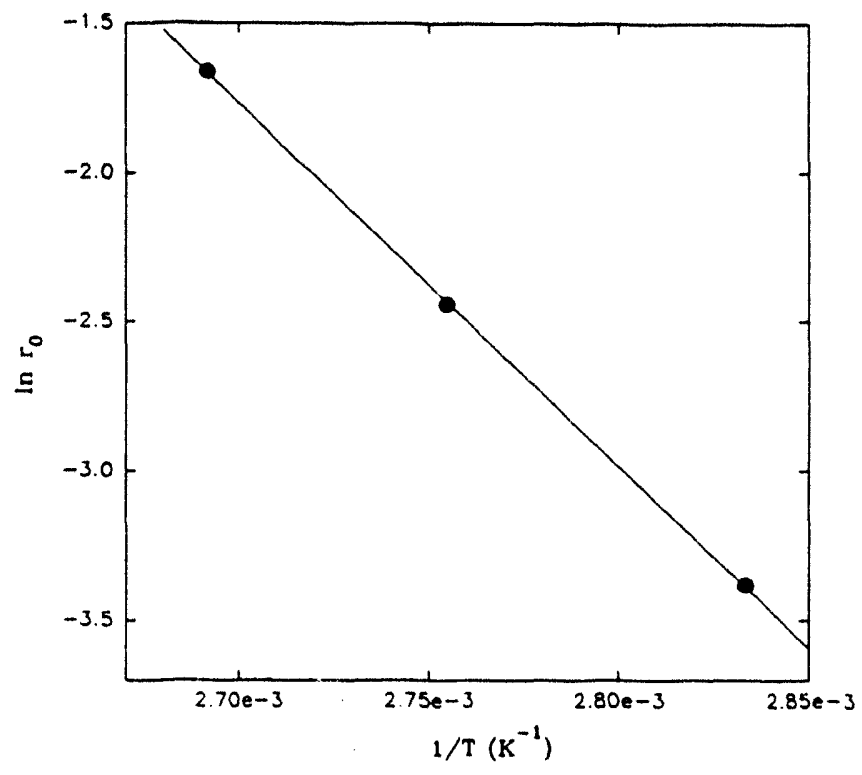

Figure 3-5. Arrhenius plot for the 4-methyl-1,3-dioxolane formation reaction.

In one experiment Amberlyst 15 was used instead of Amberlite IR-120. The reaction conditions were similar to those of Experiment $B$ in Table 3-2. The reaction kinetics was ca. $50 \%$ faster than with Amberlite IR-120, but the Amberlyst 15 catalyst was more affected by attrition at the high rates of stirring used in the experiments.

A kinetics experiment for the transacetalization reaction was carried out at a temperature of $57 \pm 2{ }^{\circ} \mathrm{C}$. The reaction took place in a solution of $4 \mathrm{md}$ in methanol. Besides the desired reaction, side reactions occurred, leading to the formation of several by-products. Figure 3-6 shows the amount of propylene glycol formed as a function of time. The initial rate calculated from the slope of the plot is $29 \mathrm{mmol} / \mathrm{kg}_{\mathrm{IR}-120} \mathrm{~min}$. Attempts to identify the byproducts by GC/MS were unsuccessful. The by-products have a longer residence time on the GC column than propylene glycol, indicating that they are high-molecular-weight compounds. A chromatogram is shown in Figure 3-7. The by-products are observed only when methanol and $4 \mathrm{md}$ are in contact with a catalyst. Perhaps they are the products of incomplete or alternate transacetalization reactions, involving coupling of two propylene glycol groups with one formaldehyde group. The chromatogram in Figure 3-7 shows that the by-products are 


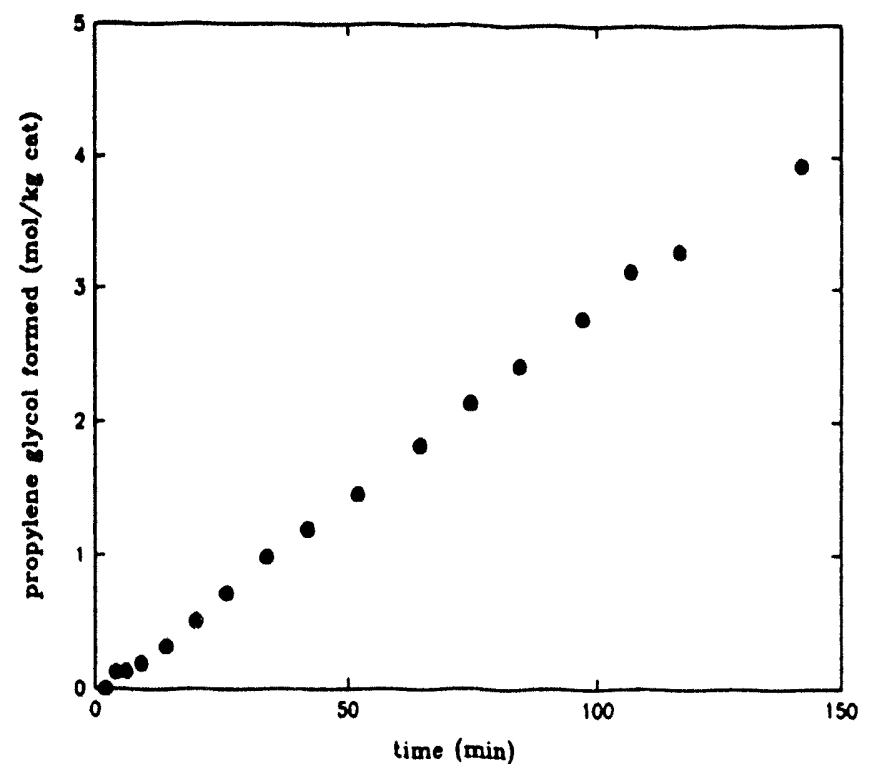

Figure 3-6. Kinetics of the reaction between 4-methyl-1,3-dioxolane and methanol to form propylene glycol and methylal, at $57 \pm 2{ }^{\circ} \mathrm{C}$.

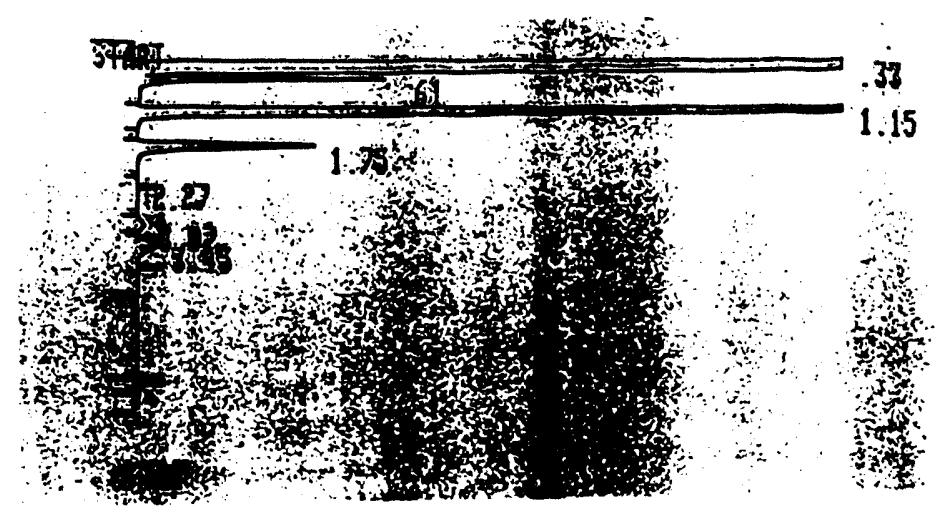

$\begin{array}{lrr}\text { Compound } & \text { R.T. } & \text { Area\% } \\ \text { methanol } & 0.33 & 90.033 \\ \text { methylal } & 0.61 & 0.439 \\ \text { 4md } & 1.15 & 8.723 \\ \text { prop.glycol } & 1.75 & 0.613 \\ ? & 3.07 & 0.040 \\ ? & 3.45 & 0.148\end{array}$

Figure 3-7. Gas chromatogram of the reaction mixture during the transacetalization reaction formed in concentrations as high as $25 \%$ (chromatogram area\%, with an FID detector) of the propylene glycol concentration. These compounds do not form in such high quantities when 
water is present. Attempts to concentrate these compounds by distillation of the reaction mixture in which they appear led to their decomposition at temperatures above $80^{\circ} \mathrm{C}$. From analysis of the distilate fractions collected at regular intervals it appears that this decomposition results in the formation of $4 \mathrm{md}$ and methanol, and methylal in smaller quantities. Thus it may be possible to recycle the by-products in an actual process.

The kinetics of the methylal hydrolysis reaction were determined in one experiment at $45^{\circ} \mathrm{C}$. Higher temperatures were impractical due to the low boiling point of methylal. The extent of reaction is plotted against time in Figure 3-8. The initial rate of this reaction is 1.0

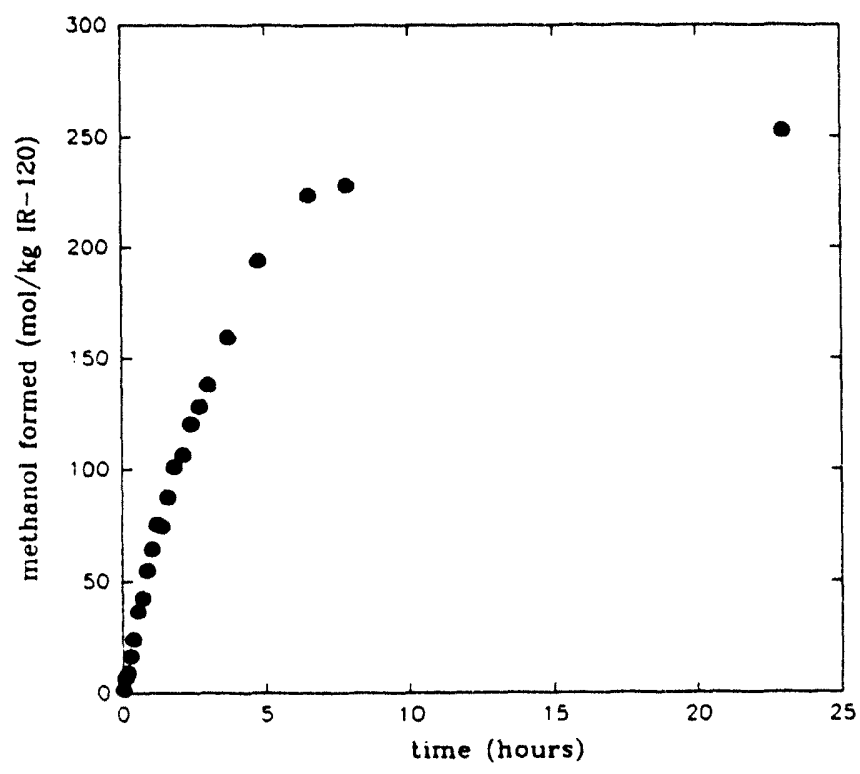

Figure 3-8. Kinetics of the methylal hydrolysis reaction at $46 \pm 1{ }^{\circ} \mathrm{C}$.

$\mathrm{mol} / \mathrm{kg}_{\mathrm{IR}-120} \mathrm{~min}$.

The acetalization reaction between acetaldehyde and propylene glycol to form $24 \mathrm{dmd}$ was studied in one kinetics experiment at $60 \pm 1{ }^{\circ} \mathrm{C}$. A graph of the amount of $24 \mathrm{dmd}$ formed vs. time is shown in Figure 3-9. The volatility of acetaldehyde limits the temperature at which the kinetics can be studied. Therefore, an activation energy for this reaction was not found. If it is assumed that the reaction is first-order in each of the reactants, as was the case for the formaldehyde reaction, then the equivalent rate expression is given in Equation 4-3. The value of the reaction-rate constant $k\left(60^{\circ} \mathrm{C}\right)$, the product of the pre-exponential factor $k_{\circ}$ and the 


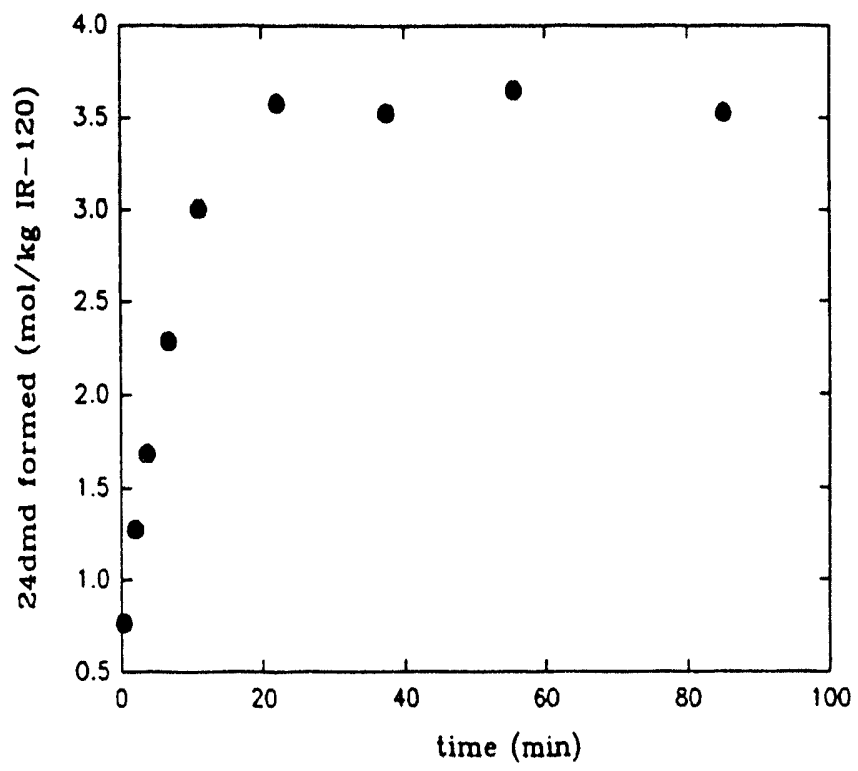

Figure 3-9. Kinetics of the reaction between 1,2-propanediol and acetaldehyde to form 2,4dimethyl-1,3-dioxolane, at $60 \pm 1^{\circ} \mathrm{C}$.

$$
r=k_{0} \cdot e^{-E_{A} / R T} \cdot w_{\text {eat }} \cdot[g l y c o l]\left[C H_{3} C H O\right]
$$

exponential expression at $60^{\circ} \mathrm{C}$, is $0.905 \mathrm{~kg}^{2} / \mathrm{mol} \mathrm{min}$. The equivalent $\mathrm{k}\left(60^{\circ} \mathrm{C}\right)$ calculated from Equation $4-1$ is $0.165 \mathrm{~kg}^{2} / \mathrm{mol} \mathrm{min}$, which shows that the acetalization reaction with acetaldehyde is much faster than with formaldehyde. An explanation of this difference may be that the concentration of free formaldehyde in a formaldehyde solution is very small, hydrates and oligomers accounting for the majority of the total formaldehyde present. Formaldehyde may therefore not be as readily available for reaction as acetaldehyde is.

\subsection{Screening of solvents for extraction}

Selected solvents were screened for their effectiveness in a reaction/extraction process. Table 3-3 lists $D_{24 d m d}$ and $D_{\text {MecHo, the distribution ratios between the organic and aqueous }}$ phases for the two compounds of interest. All solvents screened have low solubilities in water. 


\begin{tabular}{|c|c|c|c|}
\hline Solvent & $\begin{array}{l}\text { Boiling point } \\
\left({ }^{\circ} \mathrm{C}\right)\end{array}$ & $D_{24 d m d}$ & $\mathrm{D}_{\text {MeCRO }}$ \\
\hline Toluene & 110.6 & 10.1 & 0.51 \\
\hline o-Xylene & 144.4 & 7.7 & 0.42 \\
\hline Ethylbenzene & 136.2 & 7.1 & 0.36 \\
\hline n-Octane & 125.7 & 2.8 & 0.11 \\
\hline Dibutylether & 142 & 4.4 & 0.26 \\
\hline Methylcyclohexanone & 168 & 7.4 & 0.90 \\
\hline
\end{tabular}

To minimize the solvent flowrate in an extraction process a high value of $D_{24 d m d}$ is essential. Also, a low value of $D_{\text {MeCHO }}$ is desirable, to keep as much acetaldehyde as possible in the aqueous phase (where reaction takes place), and to minimize costs associated with downstream separations. Judging by these criteria, aromatic hydrocarbons appear to be the best solvents of those examined. The choice of a high-boiling solvent such as 0 -xylene or ethylbenzene rather than toluene makes for an easier separation of $24 \mathrm{dmd}$ from the organic phase.

\subsection{Simultaneous reaction and extraction}

A reaction of propylene glycol to $24 \mathrm{dmd}$ in an aqueous phase, with simultaneous extraction into a toluene phase, was carried out at $38^{\circ} \mathrm{C}$. The aqueous-phase concentrations of propylene glycol and $24 \mathrm{dmd}$ and the organic-phase concentration of $24 \mathrm{dmd}$ are plotted as functions of time in Figure 3-10. Extraction equilibrium is attained on a time-scale of ca. 10 minutes; the reaction proceeds to a near-equilibrium state in $c a .40$ minutes. The overall conversion in this one equivolume batch extractor/reactor was ca. $88 \%$, and the recovery into the toluene phase ca. $80 \%$. 


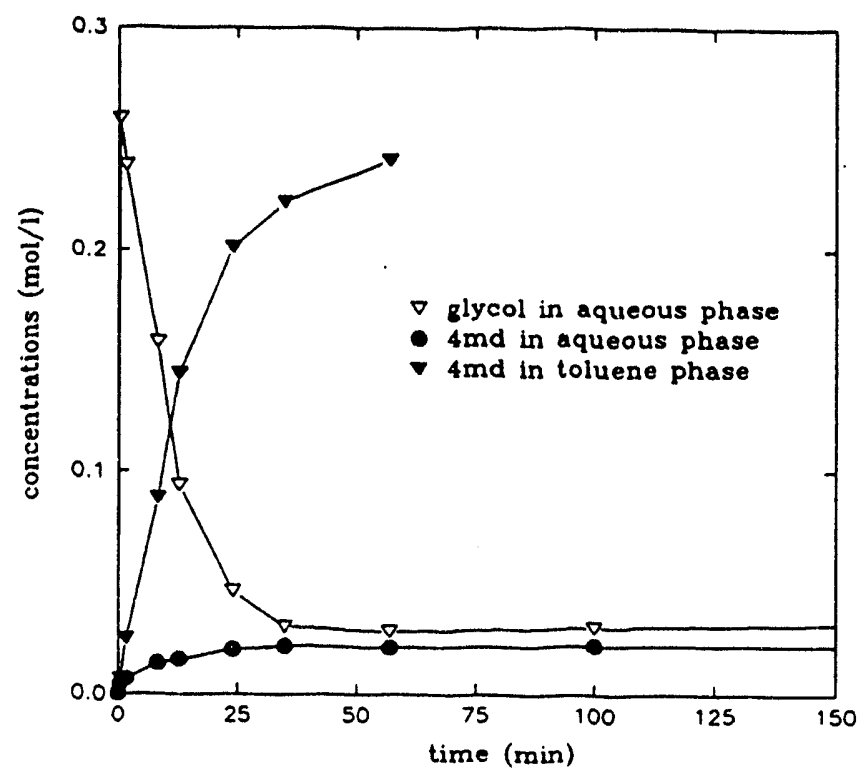

Figure 3-10. Aqueous- and toluene-phase concentrations of 1,2-propanediol and 2,4-dimethyl1,3 -dioxolane during simultaneous reaction and extraction at $38^{\circ} \mathrm{C}$.

\subsection{Liquid-liquid equilibria in dioxolane-water systems}

The compositions of the dioxolane-rich and water-rich phases in the liquid-liquid equilibria between (a) $4 \mathrm{md}$ and water and (b) $24 \mathrm{dmd}$ and water are shown in Table 3-4. The measurements in system (a) were done for a range of temperatures, from room temperature up to around the atmospheric bubble point.

Liquid-liquid equilibria were measured in the ternary system methanol/4md/water, to investigate how the addition of methanol affects the liquid-liquid equilibrium of $4 \mathrm{md} /$ water. The concentrations of the water-rich phase could be quantified considerably more accurately than those of the dioxolane-rich phase. Ternary results are given in Table 3-5.

From the data in Table 3-5 it can be inferred that the addition of $c a .10$ wt\% methanol to any $4 \mathrm{md} /$ water system will serve to homogenize the mixture. 


\begin{tabular}{||c|r|r||}
\hline \hline Table 3-4. & \multicolumn{3}{|c|}{$\begin{array}{l}\text { Composition (weight fractions) of } \\
\text { equilibrium liquid phases in water-dioxolane } \\
\text { systems }\end{array}$} \\
\hline Temperature $\left({ }^{\circ} \mathrm{C}\right)$ & aqueous w dioxolane & organic w dioxolane \\
\hline \hline A. 4md - water & 0.279 & 0.957 \\
\hline 28 & 0.269 & 0.934 \\
\hline 50 & 0.270 & 0.924 \\
\hline 63 & 0.274 & 0.919 \\
\hline 70 & & \\
\hline B. 24dmd - water & 0.21 & 0.962 \\
\hline 25 & & \\
\hline
\end{tabular}

Table 3-5. Liquid-liquid equilibrium data in the ternary system methanol (1)$4 \mathrm{md}(2)$ - water (3) at $24^{\circ} \mathrm{C}$.

\begin{tabular}{|r|r|r|r||}
\hline \multicolumn{2}{|c|}{ top phase } & \multicolumn{2}{|c|}{ bottom phase } \\
\hline$w_{1}^{\prime}$ & $w_{2}^{\prime}$ & $w_{1} "$ & $w_{2} "$ \\
\hline 0.019 & $?$ & 0.050 & 0.380 \\
\hline 0.027 & 0.88 & 0.071 & 0.393 \\
\hline 0.042 & 0.96 & 0.087 & 0.479 \\
\hline 0.064 & 0.93 & 0.105 & 0.583 \\
\hline Concentrations of first homogeneous mixture & 0.652 & & \\
\hline 0.101 & \multicolumn{3}{|c|}{0} \\
\hline
\end{tabular}

The concentrations of the aqueous and organic phases in the binary liquid-liquid equilibrium between 2,4-dimethyl-1,3-dioxolane and water at $25^{\circ} \mathrm{C}$ are 21 and $96.2 \mathrm{wt} \% 24 \mathrm{dmd}$, respectively, i.e. the miscibility gap is somewhat larger than for the $4 \mathrm{md}$-water system. 


\subsection{Vapor-liquid equilibria}

\section{$4 \mathrm{md} /$ water and methanol/4md/water}

Binary VLE data were obtained in the limited ranges of compositions, on both sides of the miscibility envelope, in which phase splitting did not occur in either the vapor phase condensate or the liquid phase, To investigate intermediate compositions, methanol was added to the Othmer still as a homogenizer. Appendix $\mathrm{C}$ lists all equilibrium data measured. Figure 3-11 shows an $x$-y diagram of the binary system, with ternary data presented as pseudo-binary

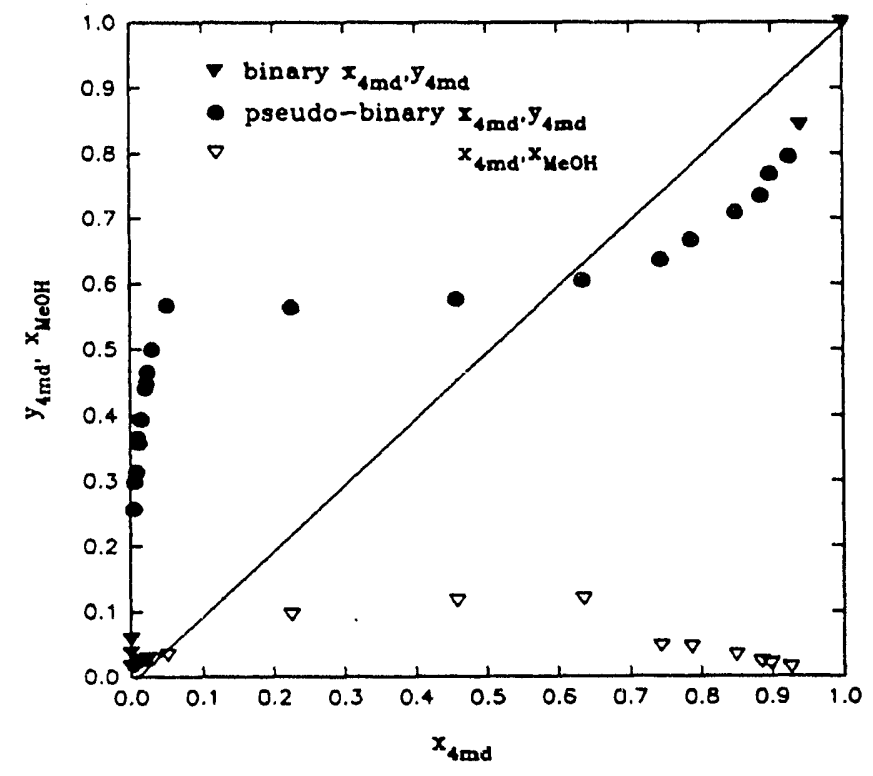

Figure 3-11. Vapor-liquid equilibrium for 4-methyl-1,3-dioxolane and water, binary data $(x, y)$ and pseudo-binary data $\left(\mathrm{x}^{\mathrm{pb}}, \mathrm{y}^{\mathrm{pb}}\right)$. For the latter, the liquid-phase methanol concentration is plotted as well.

data by using $x_{2}{ }^{p b}=x_{2} /\left(x_{2}+x_{3}\right)$ and $x_{3}{ }^{p b}=x_{3} /\left(x_{2}+x_{3}\right)$ and equivalent expressions for $y_{2}{ }^{p b}$ and $y_{3}{ }^{p b}$. The system shows an azeotrope at a composition of $c a .60 \mathrm{~mol} \% 4 \mathrm{md}$. At low concentrations of $4 \mathrm{md}$ in water, the relative volatility $\alpha_{23}$ is ca. 100 . 


\section{4dmd/water}

Two equilibrium data points at low concentrations of $24 d m d$ were measured for this binary system. The data are included in Appendix C. Both data points indicate a relative volatility $\alpha_{12}$ of $c a .33$.

\section{4dmd/toluene}

A series of data points at low to intermediate concentrations of $24 \mathrm{dmd}$ in toluene were measured. The data are included in Appendix $C$ and shown in Figure 3-12. They are well represented by the curve for an ideal mixture with $\alpha_{12}=1.76$.

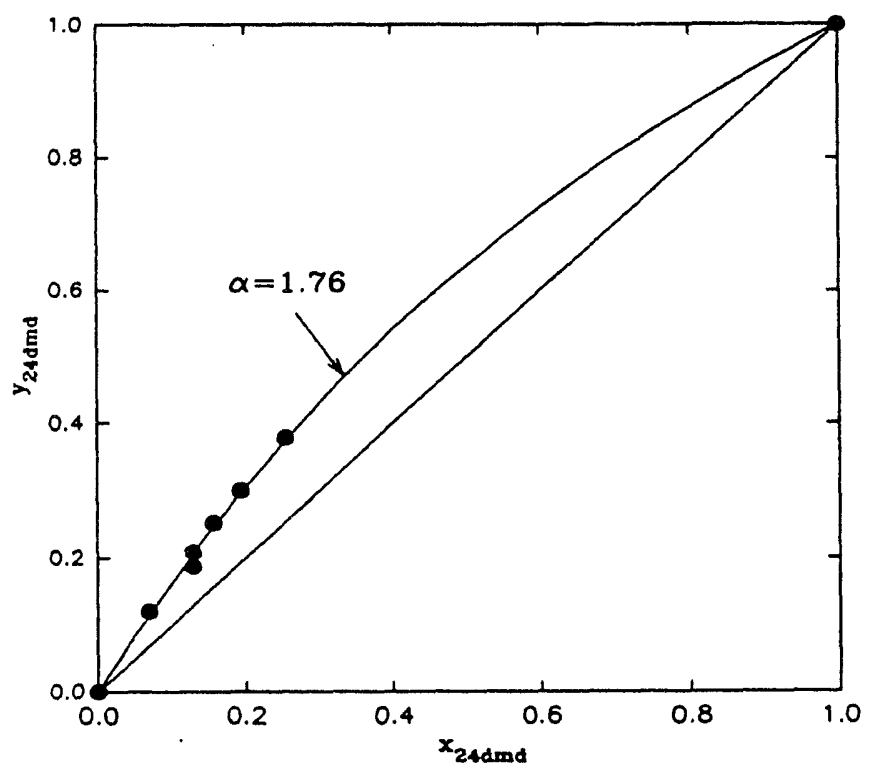

Figure 3-12. Vapor-liquid equilibrium data in the system 2,4-dimethyl-1,3-dioxolane and toluene. 


\section{Process evaluation}

\subsection{Evaluation of the formaldehyde process}

The recovery of propylene glycol from dilute aqueous solution using formaldehyde involves an acetalization reaction to form $4 \mathrm{md}$, transacetalization of $4 \mathrm{md}$ with methanol to form methylal and propylene glycol, and hydrolysis of methylal to re-form formaldehyde and methanol (see Figure 1-1). The first step processes a large volume of aqueous solution; the second and third steps process much smaller organic streams. Energy expenditure is therefore expected to be largest in the first step.

The acetalization step is envisioned to be a reactive distillation column, with solid ion exchange resin as a catalyst. In Section 3.3 it was determined that the reaction is first order in both propylene glycol and formaldehyde. If the feed is stoichiometric this leads to a secondorder reaction, with very slow kinetics at low concentrations. In a plug-flow reactor operating at $95^{\circ} \mathrm{C}$, with a feed of $0.263 \mathrm{M}(2 \mathrm{wt} \%)$ propylene glycol and $0.263 \mathrm{M}$ formaldehyde, a $99 \%$ conversion of the glycol is reached in 72 minutes. This is the best-case scenario, assuming equal weights of catalyst and solution within the reactor and negligible reverse reaction at all times. Since a reaction time of this order would be prohibitive, an excess of formaldehyde would be necessary to carry out the reactior. to a satisfactory conversion. Using a molar ratio of formaldehyde to glycol of 2 , the reaction time for $99 \%$ conversion is reduced to 2.8 minutes, which is a reasonable residence time inside the catalytic zone of a reactive column. However, now there is the difficult problem of removing the formaldehyde from the spent broth. Senkus (1946a) treated the spent broth by reacting it with an excess of methanol, converting the formaldehyde to methylal and recovering the methylal by distillation. If the excess of formaldehyde is small, the effluent may be biologically treated to remove the formaldehyde without attempting to recover it. But although these solutions to the engineering problem are available, they are not likely to lead to an economically attractive process.

Acetalization with formaldehyde therefore appears not to be sufficiently attractive for use in a process meant to improve upon the thermal efficiency of simple distillation processes. 


\subsection{Evaluation of the acetaldehyde process - distillative route}

With acetaldehyde, some of the problems with formaldehyde are avoided. Excess acetaldehyde is recovered at the top of the column rather than at the bottom, so that contamination of the spent broth with the aldehyde would not be a problem (see Figure 1-2). Since acetaldehyde has such a large volatility, most of it distributes into the vapor phase. A large excess of acetaldehyde is therefore needed to achieve a reasonable liquid-phase concentration.

ChemCad, a computer program for flowsheeting and process modeling (see Appendix D), was used to model somewhat crudely the reactive distillation of a 1.5 wt\% solution of propylene glycol. This solution is fed near the top of the column, the stages above it being used to reduce the water content of the distillate. Acetaldehyde vapor is fed near the bottom of the column. The bottom stages serve to strip $24 \mathrm{dmd}$ and acetaldehyde out of the spent broth. The stages between the two feeds constitute the reaction zone. In ChemCad, this zone is modeled by a number of equilibrium stages. Liquid sidestreams are taken from several of these stages, passed through a reactor that attains reaction equilibrium, and fed back to the stage below.

The ChemCad output of a simulation using equal mass flow streams of aqueous and aldehyde feeds is presented in Appendix D. The most important result is that recovery of glycol as $24 \mathrm{dmd}$ in the distillate does not exceed $80 \%$ of the theoretical yield. The number of stages and the reflux rate were optimized to maximize the recovery, so that the only way to increase the yield would be to increase the acetaldehyde flowrate above its already large value.

ChemCad was also used to model the reverse reaction, the direct hydrolysis of $24 \mathrm{dmd}$. Typical results are presented in Appendix D. This reaction is more suited to reactive distillation, since the volatilities of the reactants (water and $24 \mathrm{dmd}$ ) are between those of the products (propylene glycol and acetaldehyde). Therefore, the reactants can be kept inside the reaction zone, while the products leave in the distillate and the bottoms product.

Since an adequate design for the reactive distillation constituting the first step in this version of the acetaldehyde process could not be found, reactive distillation does not appear to be attractive as the operation to treat the dilute broth. Higher-boiling aldehydes such as propionaldehyde or butyraldehyde, which distribute more favorably between the liquid and 
the vapor phase, are not applicable in this process due to their tendency to participate in aldol condensation reactions (see section 2.2 and Roxburgh, 1951).

\subsection{Evaluation of the acetaldehyde process - extractive route}

The problems with the distillative version of the acetaldehyde process are caused primarily by the tendency of acetaldehyde to distribute into the vapor phase. An operation without a vapor phase, e.g. extraction, would eliminate this problem. Solvents exhibiting high distribution ratios for $\mathbf{2 4 d i n d ~ a n d ~ l o w ~ o n e s ~ f o r ~ a c e t a l d e h y d e ~ w e r e ~ i d e n t i f i e d . ~ T h e ~ d i s t r i b u t i o n ~}$ of $24 \mathrm{dmd}$ is greatest into toluene; however, the measured VLE data for the $24 \mathrm{dmd} /$ toluene system show a relative volatility of just 1.76 , which would make a separation of $24 \mathrm{dmd}$ out of a toluene extractant costly. Ethylbenzene or other higher-boiling aromatic hydrocarbons would therefore be more suitable.

The applicability of continuous countercurrent extraction combined with reaction was investigated theoretically. Differential equations describing the reaction and extraction were derived and solved using a Turbo Pascal program. This work is documented in Appendix E. The outcome of the study was that, given enough reaction time in the extractor, the operation can successfully recover propylene glycol as $24 \mathrm{dmd}$ to any specified degree.

A continuous countercurrent extraction operation with a simultaneous heterogeneously catalyzed reaction is difficult to envision. Therefore, the operation of a series of mixersettlers, connected in an overall countercurrent scheme, was also modeled with a Turbo Pascal program. Phase equilibrium was assumed to be attained instantaneously, reaction being the rate-limiting process. Equations, program code and results are presented in Appendix E. The outcome of this study was that, given a sufficient number of mixer-settlers with a sufficient overall residence time, this operation can also recover propylene glycol as $24 \mathrm{dmd}$ to any degree specified.

Downstream processing in this extractive process includes stripping acetaldehyde out of both the spent broth and the organic phase, recovering the $24 \mathrm{dmd}$ out of the organic phase and recovering propylene glycol by reactive distillation, as described in Section 1.4.4. ChemCad was used to model these distillation operations; details of this ef fort are given in Appendix D. 
40

The study shows that the energy input for downstream processing corresponds to $42 \%$ of the energy input of a triple-effect evaporation process. The energy input for the actual reaction/extraction equipment is difficult to estimate, but is probably not very high. This means that the reaction/extraction process with acetaldehyde has a considerable energy advantage over direct distillation. This advantage is of fet by higher equipment costs and the costs and possible contamination problems involved with the use of acetaldehyde and an aromatic solvent in the process. 


\section{Conclusion}

Propylene glycol may be converted to a cyclic acetal by reaction with an aldehyde. In this reaction both hydroxyl groups on the glycol are converted, resulting in a product of much lower hydrophilicity, which can be separated from aqueous solution by distillation or extraction. Chemical equilibrium in the acetalization reaction does not correspond to a high degree of conversion. Therefore, it is necessary to remove the product acetal during the reaction, by simultaneous distillation or extraction.

The product of the reaction between formaldehyde and propylene glycol, 4-methyl-1,3dioxolane, has a high relative volatility in dilute aqueous solutions. However, the equilibrium in such a dilute system is such that an excess of formaldehyde would be needed for effective recovery of propylene glycol in a reactive distillation process. The residual formaldehyde would be difficult to separate from the aqueous solution, adding considerable cost and complexity to such a process.

Acetaldehyde reacts with propylene glycol to form 2,4-dimethyl-1,3-dioxolane. The relative volatility of acetaldehyde is high over aqueous solutions, so that an excess quantity of acetaldehyde may be used in a process without serious separation problems. Due to unfavorable equilibrium and unfavorable distribution of acetaldehyde between the liquid and the vapor phase, very large flows of acetaldehyde would be required to achieve an acceptable level of glycol recovery in a reactive distillation process. A process which combines reaction and extraction, in which acetaldehyde is present only in a liquid phase, is therefore more attractive. Kinetics studies indicate that such an extraction would proceed at a sufficiently high rate to be carried out in equipment of practical size. The energy required for the necessary separations af ter the extraction step was calculated by process simulation to be 35.1 $\mathrm{MJ} / \mathrm{kg}$ glycol, compared to $84.8 \mathrm{MJ} / \mathrm{kg}$ glycol for triple-ef fect distillation. The reduced energy load in a reaction/extraction process would be of fset by increased capital costs.

The concept of cyclic acetalization as part of a separation route can be extended to other poly-hydroxy compounds. Tink and Neish (1951) reacted a variety of chemicals, including glycols, glycerol, saccharides and sugar alcohols with butyraldehyde in an extractive separation process. In their work the butyraldehyde serves as both an extractant and a 
42

reactant, and butyraldehyde losses posed a significant problem due to side reactions. A process using acetaldehyde as a reactant combined with a separate solvent for the extraction would avoid losses of this type, while increasing complexity and separation costs of the process. 


\section{Literature references}

Aftalion, F.; Hellin, M; Coussemant, F. Étude de l'hydrolyse en milieu acide des acétals linéaires et cycliques. I. - Acétals linéaires et dioxolannes substitués. Bull. Soc. Chim. Fr. $1965,1497$.

Arenson, D.R.; King, C.J. Separation of low molecular weight alcohols from dilute aqueous solutions by reversible chemical complexation. Ph.D. Thesis. LBL report 24944, 1989.

Astle, M.J.; Zaslowsky, J.A.; Laf yatis, P.G. Catalysis with cation-exchange resins. Preparation of 1,3-dioxolanes and 1,3,6-trioxocanes. Ind. Eng. Chem. 1954, 46, 787.

Cameron, D.C.; Cooney, C.L. A novel fermentation: The production of $R(-)-1,2$-propanediol and acetol by clostridium thermosaccharolyticum. Biotechnology 1986, 4, 651 .

Cameron, D.C; Tong, I-T.; Cockrem, M. Microbial production of propanediols. Proceedings Corn Util. Conf. St. Louis, MO, 1990, 1.

Curme, G.O., Ed. Glycols; Reinhold: New York, 1952, 262.

DeGarmo, J.L.; Parulekar, V.N.; Pinjala, V. Consider reactive distillation. Chem. Eng. Progr. $1992(3), 43$.

Flato, J.; Hoffmann, U. Development and start-up of a fixed bed reaction column for manufacturing antiknock enhancer MTBE. Chem. Eng. Technol. 1992, 15, 193.

Gmehling, J.; Onken, U; Arlt, W. Eds. Vapor-liquid equilibrium data collection, Vol. 1; Dechema: Flushing, NY, 1981.

Jones, E.M. Jr. Contact structure for use in catalytic distillation. U.S. Patent 4,439,350, Mar. 27, 1984.

Koskikallio, J.; Whalley, E. Pressure effect and mechanism in acid catalysis. Part 2. Hydrolysis of formals, acetals, and ethyl orthoformate. Trans. Faraday Soc. 1959, 55, 809.

Löbering, J.; Fleischmann, A. Die Kinetik polymerer Aldehyde, VII. Mitteil.: Die Verseifungsgeschwindigkeit der Formaldehydacetale. Berichte 1937, 70, 1713.

Lucas, H.J.; Mitchell, F.W.; Scully, C.N. Cyclic phosphites of some aliphatic glycols, J. Am. Chem. Soc. $1950,72,5496$.

McIntyre, D.; Long, F.A. Acid-catalyzed hydrolysis of methylal. I. Influence of strong acids and correlation with Hammett acidity function. J. Am. Chem. Soc. 1954, 76, 3240. 
Munson, C.L.; King, C.J. Ind. Eng. Chem. Process. Des. Dev. 1984, 23, 109.

Roxburgh, J.M. Extraction of polyhydroxy compounds from dilute aqueous solutions by cyclic acetal formation. IV. Recovery of n-butyraldehyde. Can. J. Technol. 1951, 30, 72.

Salomaa, P; Kankaanperä, A. The hydrolysis of 1,3-dioxolan and its alkyl-substituted derivatives. Part I. The structural factors influencing the rates of hydrolysis of a series of methyl-substituted dioxolans. Acta Chem. Scand. 1961, 15, 871.

Senkus, M. Recovery of 2,3-butanediol produced by fermentation. Ind. Eng. Chem. 1946a, 38, 913.

Senkus, M. Process for recovery of dihydric alcohols. U.S. Patent 2,406,713, Aug. 27, $1946 \mathrm{~b}$.

Smith, L.A. Catalytic distillation structure. U.S. Patent 4,443,559, Apr. 17, 1984.

Tink, R.R.; Neish, A.C. Extraction of polyhydroxy compounds from dilute aqueous solutions by cyclic acetal formation. I. An investigation of the scope of the process. Can. J. Technol. 1951, 29, 243.

Tink, R.R.; Spencer, E.Y.; Roxburgh, J.M. Extraction of polyhydroxy compounds from dilute aqueous solutions by cyclic acetal formation. II. The Batch extraction of glycerol. Can. J. Technol. 1951, 29, 250.

Tink, R.R.; Roxburgh, J.M. Extraction of polyhydroxy compounds from dilute aqueous solutions by cyclic acetal formation. III. The continuous extraction of glycerol. Can.J. Technol. 1951, 29, 269.

Wagner, F.S. Jr. Glycols in Encyclopedia of Chemical Technology, 3rd Ed., Vol 11. Wiley \& Sons: New York, 1978, p. 933-962.

Walker, J.F. Formaldehyde, 3rd Ed.; ACS Monograph Series: Huntington, NY, 1975.

Willy, W.E.; Binsch, G.; Eliel, E.L. Conformational analysis. XXIII. 1,3-dioxolanes. J. Am. Chem. Soc. 1970, 92, 5394. 
Appendix A. Chemicals used in experimental work

\begin{tabular}{|c|c|c|}
\hline Chemical name & Manufacturer & Purity indication \\
\hline 1,2-propanediol & Aldrich Chemical Co. & $99 \% 1$ \\
\hline methanol & Fisher Scientific & certified A.C.S. grade \\
\hline ethanol (absolute) & Quantum Chemical & 200 proof \\
\hline formaldehyde (formaline) & Fisher Scientific & $\begin{array}{l}37 w t \% \text { formaldehyde, in } \\
\text { aqueous solution with } \\
\text { methanol stabilizer }\end{array}$ \\
\hline acetaldehyde & Fisher Scientific & reagent grade, $99.5 \%$ \\
\hline propanal & MCB & b.p. $47-49^{\circ} \mathrm{C}$ \\
\hline methylal (dimethoxymethane) & Aldrich Chemical Co. & $99 \%$, b.p. $41-42^{\circ} \mathrm{C}$ \\
\hline toluene & Aldrich Chemical Co. & b.p. $110.3-110.8^{\circ} \mathrm{C}$ \\
\hline 0 -xylene & MCB & b.p. $143.5-144.5^{\circ} \mathrm{C}$ \\
\hline ethylbenzene & Fisher Scientific & $99 \%$ \\
\hline
\end{tabular}

${ }^{1} \mathrm{Karl}$ Fischer titration shows no water 
Appendix B. Analytical methods

\section{Gas chromatography}

A gas chromatographic analysis technique was developed for the quantification of propylene glycol and other organic chemicals in aqueous solution. A Varian Model 3700 gas chromatograph was used throughout. Samples of $1 \mu$ l volume were injected onto a $1 / 8^{\mathrm{n}}$ 6-ft stainless steel column packed with Waters Porapak PS packing material, 80-100 mesh. For analysis of propylene glycol, the column temperature was set at $185^{\circ} \mathrm{C}$. For the analysis of more volatile chemicals such as methanol and methylal, a lower temperature was sometimes chosen. A flame-ionization detector (FID) was used in combination with a Hewlett Packard 3390A Integrator to generate a chromatogram and to obtain quantitative results. Propylene glycol, ethanol and $4 \mathrm{md}$ exhibited linear responses on the FID over a large range of concentrations.

\section{Karl Fisher titration}

The water content of organic phases was measured using a Quintel Computrac MS-1 automated Karl Fisher (KF) titrator. The KF solvent and titrant solutions were obtained from GFS Chemicals, Inc. In most cases, methanol-free KF solvent was used, allowing titration of aldehyde-and ketone-containing solutions. The titration was calibrated regularly by in jections of pure water.

\section{Formaldehyde titration}

The concentration of formaldehyde in aqueous solutions was determined using a modification of the sulfite method described by Walker (1975). A few drops of thymolphthalein indicator were added to a beaker containing ca. $20 \mathrm{ml}$ of a $1 \mathrm{M}$ sodium sulfite solution. To this solution $0.1 \mathrm{M} \mathrm{HCl}$ was added until the dark blue color disappeared. A small volume (up to $1 \mathrm{ml}$ ) of the sample to be analyzed was weighed into the beaker. The hydroxide generated in the reaction between sulfite and formaldehyde was titrated with $0.1000 \mathrm{~N} \mathrm{HCl}$ until the disappearance of the blue color. Since the color transition was not very sharply 
defined, a pH probe was used in all titrations for equilibrium studies, starting with a pH 9.50 sodium sulfite solution and titrating back to an endpoint of $\mathrm{pH} 9.50$.

\section{Gas chromatography coupled with mass spectrometry (GC/MS)}

A Hewlett Packard Model 5890A gas chromatograph coupled with a Model 5970 series Mass Selective Detector was used to identify components of reaction mixtures. The components were separated in a capillary column (J\&W Scientific, $30 \mathrm{~m} \times 0.25 \mathrm{~mm}$ i.d., coated with $0.25 \mu \mathrm{m}$ of DB5 stationary phase), using temperature programming between $30^{\circ} \mathrm{C}$ and $150^{\circ} \mathrm{C}$, and then detected with a mass spectrometer. The emergence of species from the capillary column was indicated by peaks on the total ion chromatogram. Mass spectra of selected species could then be generated and printed.

No mass spectrometer turn-on lag time was defined, since some of the species to be analyzed emerged before the solvent. To a void loss of pressure in the mass spectrometer when the solvent peak emerged, small in jection volumes $(c a .0 .2 \mu \mathrm{l})$ were used. 
Appendix C. Experimental vapor-liquid equilibrium data

1. methanol (1)/4-methvl-1.3-dioxolane (2)/water (3)

\begin{tabular}{|c|c|c|c|c|c|c|}
\hline$T$ & $x_{\mathrm{MeOH}}$ & $x_{\text {4md }}$ & $\mathrm{y}_{\mathrm{MeOH}}$ & $y_{4 m d}$ & $x_{\text {Amd }}{ }^{\mathrm{pb}}$ & $y_{4 m d^{p b}}$ \\
\hline 99.5 & & 0.0002 & & 0.017 & & \\
\hline 99.2 & & 0.00039 & & 0.037 & & \\
\hline 99.1 & & 0.00057 & & 0.058 & & \\
\hline 91.3 & 0.0168 & 0.0045 & 0.1475 & 0.2190 & 0.0045 & 0.2568 \\
\hline 90.5 & 0.0164 & 0.0052 & 0.1441 & 0.2553 & 0.0053 & 0.2983 \\
\hline 89.0 & 0.0193 & 0.0080 & 0.1320 & 0.2723 & 0.0082 & 0.3138 \\
\hline 87.8 & 0.0211 & 0.0098 & 0.1375 & 0.3154 & 0.0101 & 0.3657 \\
\hline 86.7 & 0.0223 & 0.0115 & 0.1075 & 0.3197 & 0.0118 & 0.3581 \\
\hline 85.5 & 0.0236 & 0.0142 & 0.1056 & 0.3517 & 0.0145 & 0.3932 \\
\hline 83.8 & 0.0256 & 0.0191 & 0.1068 & 0.3936 & 0.0196 & 0.4407 \\
\hline 83.3 & 0.0277 & 0.0212 & 0.1097 & 0.4002 & 0.0219 & 0.4495 \\
\hline 82.5 & 0.0276 & 0.0228 & 0.1087 & 0.4146 & 0.0234 & 0.4651 \\
\hline 81.1 & 0.0276 & 0.0291 & 0.1026 & 0.4485 & 0.0300 & 0.4997 \\
\hline 79.8 & & 0.1484 & & & & \\
\hline 78.8 & & 0.1726 & & & & \\
\hline 78.2 & 0.0328 & 0.0496 & 0.0987 & 0.5103 & 0.0513 & 0.5662 \\
\hline 76.9 & & 0.2195 & & & & \\
\hline 74.0 & 0.0946 & 0.2034 & 0.1571 & 0.4742 & 0.2246 & 0.5625 \\
\hline 73.5 & 0.1165 & 0.4052 & 0.1613 & 0.4823 & 0.4587 & 0.5750 \\
\hline 72.9 & 0.1183 & 0.5601 & 0.1725 & 0.4995 & 0.6353 & 0.6036 \\
\hline 75.0 & 0.0462 & 0.7089 & 0.1007 & 0.5719 & 0.7432 & 0.6359 \\
\hline 75.4 & 0.0446 & 0.7516 & 0.1025 & 0.5981 & 0.7867 & 0.6664 \\
\hline 76.2 & 0.0319 & 0.8233 & 0.0942 & 0.6415 & 0.8505 & 0.7082 \\
\hline 77.1 & 0.0218 & 0.8669 & 0.0754 & 0.6789 & 0.8862 & 0.7342 \\
\hline 78.2 & 0.0179 & 0.8827 & 0.0660 & 0.7166 & 0.8988 & 0.7672 \\
\hline 79.4 & 0.0123 & 0.9146 & 0.0495 & 0.7547 & 0.9260 & 0.7939 \\
\hline 81.1 & & 0.9359 & & 0.8261 & 0.9415 & 0.8422 \\
\hline 84.1 & & 1.0000 & & 1.0000 & 1.0000 & 1.0000 \\
\hline
\end{tabular}


2. 2.4-dimethyl-1.3-dioxolane (1) / water (2)

\begin{tabular}{|c|c|}
\hline$x_{2 \mathrm{ddmd}}$ & $y_{2 \mathrm{dmd}}$ \\
\hline 0.00013 & 0.0045 \\
\hline 0.000095 & 0.0032 \\
\hline
\end{tabular}

3, 2,4-dimethyl-1.3-dioxolane (1) / toluene (2)

\begin{tabular}{|c|l|l|}
\hline $\mathrm{T}$ & $\mathrm{x}$ & $\mathrm{y}$ \\
\hline 103.4 & 0.253 & 0.378 \\
\hline 104.9 & 0.194 & 0.301 \\
\hline 105.8 & 0.157 & 0.252 \\
\hline 106.7 & 0.129 & 0.208 \\
\hline 107.0 & 0.129 & 0.187 \\
\hline 108.1 & 0.068 & 0.120 \\
\hline
\end{tabular}


Appendix D. ChemCad process modeling

Several processes for the recovery of propylene glycol from dilute aqueous solution were modeled using ChemCad II version 2.6 from Chemstations Inc. ChemCad is a PC software package for flowsheeting and chemical process modeling. For each of the processes investigated, the feed stream specification was identical:

$1000 \mathrm{kmol} / \mathrm{h}$ water

$3 \mathrm{kmol} / \mathrm{h}$ glycol (1.25 wt\%).

$35^{\circ} \mathrm{C}$

ChemCad has a limited database of chemical compounds; neither propylene glycol nor 24dmd were included. Ethylene glycol was used as a substitute for propylene glycol. In the case of $24 \mathrm{dmd}$, diisopropyl ether was selected as a representative substitute; it has a boiling point close to that of $24 \mathrm{dmd}$ and its binary NRTL parameters with water were adjusted so that the azeotropic composition equaled that of $24 \mathrm{dmd}$ with water.

The thermodynamics models used were NRTL for K-value calculations and Soave Redlich Kwong for enthalphy calculations. Distillations were modeled using the Scds rigorous distillation routine. ChemCad does not define a unit operation model for reactive distillation. To model such an operation, a regular distillation column was used, with liquid sidestreams from several trays being converted in equilibrium conversion reactors and fed back into the column on the tray below. ChemCad puts a limitation on the number of sidestreams allowed per column, so that for adequate modeling of a reactive column, two or more columns were sometimes defined, with a reboiler only installed on the bottom column and a condenser only on the top one. 
Simple distillation

To serve as a standard of comparison for the proposed new processes, the simple distillation of an aqueous propylene glycol solution in a single column was modeled. The column was specified to produce a 99 mol\% propylene glycol product. The fraction of glycol leaving in the distillate was negligible. The calculated reboiler duty was $45.0 \mathrm{GJ} / \mathrm{h}$. An actual evaporative process is typically carried out in a triple-effect evaporator, so that the evaporation load $(40 \mathrm{GJ} / \mathrm{h})$ is reduced to roughly a third of that value. The total energy use of the process then comes out to be $18.3 \mathrm{GJ} / \mathrm{h}$, for a separation yield of $3.00 \mathrm{kmol} / \mathrm{h}$. An overview of results is given in Table D-1.

\begin{tabular}{|c|c|}
\hline Feed composition & $\begin{array}{l}\text { water: } 1000 \mathrm{kmol} / \mathrm{h} \\
\text { propylene glycol: } 3 \mathrm{kmol} / \mathrm{h}\end{array}$ \\
\hline Number of stages & 20 \\
\hline Feed stage & 10 \\
\hline Condenser specification & total condenser, $R / D=0.01$ \\
\hline Reboiler specification & glycol purity $99 \%$ \\
\hline Pressure & 0.2 bar \\
\hline Reflux ratio & 0.01 \\
\hline Condenser duty & $-43.0 \mathrm{GJ} / \mathrm{h}$ \\
\hline Reboiler duty & $45 \mathrm{GJ} / \mathrm{h}$ \\
\hline Condensate flowrates & $\begin{array}{l}\text { water: } 1000 \mathrm{kmol} / \mathrm{h} \\
\text { propylene glycol: } 0 \mathrm{kmol} / \mathrm{h}\end{array}$ \\
\hline Bottoms flowrates & $\begin{array}{l}\text { water: } 0.03 \mathrm{kmol} / \mathrm{h} \\
\text { propylene glycol: } 3 \mathrm{kmol} / \mathrm{h}\end{array}$ \\
\hline
\end{tabular}


Reactive distillation of propylene glycol with acetaldehyde

The reactive distillation and subsequent separation of the column overhead into acetaldehyde and dioxolane were modeled. Three columns were used in the modeling of the reactive distillation, as described above; a total of nine equilibrium reaction stages were incorporated into the flowsheet in this manner. It is not advantageous to condense the overhead stream from the reactive column, since it consists mainly of unconverted acetaldehyde which is recycled in the vapor form. Therefore, the condenser on this column is a partial condenser, passing on a vapor stream to the second column. Besides acetaldehyde, this stream contains the $24 \mathrm{dmd}$ formed in the reactive column and a considerable amount of water. The products of the second column are acetaldehyde vapor (overhead) and a solution of $24 \mathrm{dmd}$ in water (bottoms).

It was difficult to achieve a high recovery of $24 \mathrm{dmd}$ with the reactive column. The unfavorable reaction equilibrium in dilute aqueous glycol solution, combined with the low vapor pressure of the resultant $24 \mathrm{dmd}$ above its even more dilute solution, causes a high volume of acetaldehyde to be required for stripping. The maximum reasonable acetaldehyde flow was taken to be a flowrate equal in mass flow to the entering glycol solution. With this much acetaldehyde, a recovery of $c a .80 \%$ of the propylene glycol as $24 \mathrm{dmd}$ was achieved. To reach that level of recovery, a considerable amount of water must be taken overhead along with the acetaldehyde and $24 \mathrm{dmd}$. The second column separates off the acetaldehyde, which is recycled as a vapor; a solution of $24 \mathrm{dmd}$ in water, which can be fed into a hydrolysis column, is the bottoms product. The reboiler duty for the reactive column was $9.40 \mathrm{GJ} / \mathrm{h}$, in the second column $0.61 \mathrm{GJ} / \mathrm{h}$. Distillation summaries are given in Tables D-2 and D-3, respectively. 


\begin{tabular}{|c|c|}
\hline Feed composition & $\begin{array}{l}\text { water: } 1000 \mathrm{kmol} / \mathrm{h} \\
\text { propylene glycol: } 3 \mathrm{kmol} / \mathrm{h} \\
\text { acetaldehyde: } 400 \mathrm{kmol} / \mathrm{h}\end{array}$ \\
\hline Number of stages & 43 in a total of 3 columns \\
\hline Feed stages & $\begin{array}{l}\text { propylene glycol solution: } 5 \\
\text { acetaldehyde: } 36\end{array}$ \\
\hline Condenser specification & partial condenser, $R / D=0.01$ \\
\hline Reboiler specification & duty $9.40 \mathrm{GJ} / \mathrm{h}$ \\
\hline Pressure & $1 \mathrm{bar}$ \\
\hline Reflux ratio & 0.01 \\
\hline Condenser duty & $-0.25 \mathrm{GJ} / \mathrm{h}$ \\
\hline Reboiler duty & $9.40 \mathrm{GJ} / \mathrm{h}$ \\
\hline Condensate flowrates & $\begin{array}{l}\text { water: } 76.80 \mathrm{kmol} / \mathrm{h} \\
\text { acetaldehyde: } 397.8 \mathrm{kmol} / \mathrm{h} \\
\text { 24dmd: } 2.397 \mathrm{kmol} / \mathrm{h}\end{array}$ \\
\hline Bottoms flowrates & $\begin{array}{l}\text { water: } 925.4 \mathrm{kmol} / \mathrm{h} \\
\text { propylene glycol: } 0.626 \mathrm{kmol} / \mathrm{h}\end{array}$ \\
\hline
\end{tabular}




\begin{tabular}{|c|c|}
\hline Feed composition & $\begin{array}{l}\text { water: } 76.80 \mathrm{kmol} / \mathrm{h} \\
\text { acetaldehyde: } 397.8 \mathrm{kmol} / \mathrm{h} \\
\text { 24dmd: } 2.397 \mathrm{kmol} / \mathrm{h}\end{array}$ \\
\hline Number of stages & 20 \\
\hline Feed stage & 10 \\
\hline Condenser specification & $0.5 \%$ of $24 \mathrm{dmd}$ lost to tops \\
\hline Reboiler specification & ratio $24 \mathrm{dmd} / \mathrm{MeCHO}=3$ in bottoms \\
\hline Pressure & $1.1 \mathrm{bar}$ \\
\hline Reflux ratio & 0.406 \\
\hline Condenser duty & $-4.56 \mathrm{GJ} / \mathrm{h}$ \\
\hline Reboiler duty & $0.61 \mathrm{GJ} / \mathrm{h}$ \\
\hline Condensate flowrates & $\begin{array}{l}\text { water: } 0.104 \mathrm{kmol} / \mathrm{h} \\
\text { acetaldehyde: } 396.97 \mathrm{kmol} / \mathrm{h} \\
\text { 24dmd: } 0.012 \mathrm{kmol} / \mathrm{h}\end{array}$ \\
\hline Bottoms flowrates & $\begin{array}{l}\text { water: } 76.70 \mathrm{kmol} / \mathrm{h} \\
\text { acetaldehyde: } 0.795 \mathrm{kmol} / \mathrm{h} \\
\text { 24dmd: } 2.385 \mathrm{kmol} / \mathrm{h}\end{array}$ \\
\hline
\end{tabular}

The hydrolysis reactive distillation was modeled as one column with four connected reactors. A high yield of propylene glycol can be achieved relatively easily in this case. The resulting mixture of propylene glycol and water must be separated in a subsequent column. The reboiler duties for these columns are $0.31 \mathrm{GJ} / \mathrm{h}$ and $3.11 \mathrm{GJ} / \mathrm{h}$, respectively. Column overviews are presented in Tables D-4 and D-5. 


\begin{tabular}{|c|c|}
\hline Feed composition & $\begin{array}{l}\text { water: } 76.70 \mathrm{kmol} / \mathrm{h} \\
\text { acetaldehyde: } 0.80 \mathrm{kmol} / \mathrm{h} \\
\text { 24dmd: } 2.385 \mathrm{kmol} / \mathrm{h}\end{array}$ \\
\hline Number of stages & 20 \\
\hline Feed stage & 8 ; reactors feeding into $10,12,14,16$ \\
\hline Condenser specification & $\begin{array}{l}0.005 \mathrm{kmol} / \mathrm{h} 24 \mathrm{dmd} \text { lost to } \\
\text { condensate }\end{array}$ \\
\hline Reboiler specification & $0.005 \mathrm{kmol} / \mathrm{h} 24 \mathrm{dmd}$ lost to bottoms \\
\hline Pressure & 1 bar \\
\hline Reflux ratio & 2.72 \\
\hline Condenser duty & $-0.25 \mathrm{GJ} / \mathrm{h}$ \\
\hline Reboiler duty & $0.31 \mathrm{GJ} / \mathrm{h}$ \\
\hline Condensate flowrates & $\begin{array}{l}\text { water: } 0.01 \mathrm{kmol} / \mathrm{h} \\
\text { acetaldehyde: } 3.17 \mathrm{kmol} / \mathrm{h} \\
\text { 24dmd: } 0.005 \mathrm{kmol} / \mathrm{h}\end{array}$ \\
\hline Bottoms flowrates & $\begin{array}{l}\text { water: } 74.32 \mathrm{kmol} / \mathrm{h} \\
\text { acetaldehyde: } 0.001 \mathrm{kmol} / \mathrm{h} \\
\text { 24dmd: } 0.005 \mathrm{kmol} / \mathrm{h} \\
\text { propylene glycol: } 2.375 \mathrm{kmol} / \mathrm{h}\end{array}$ \\
\hline
\end{tabular}




\begin{tabular}{|c|c|}
\hline Feed composition & $\begin{array}{l}\text { water: } 74.32 \mathrm{kmol} / \mathrm{h} \\
\text { propylene glycol: } 2.375 \mathrm{kmol} / \mathrm{h} \\
\text { 24dmd: } 0.005 \mathrm{kmol} / \mathrm{h}\end{array}$ \\
\hline Number of stages & 14 \\
\hline Feed stage & 7 \\
\hline Condenser specification & $0.05 \%$ glycol lost in condensate \\
\hline Reboiler specification & $99.5 \%$ pure glycol product \\
\hline Pressure & $1.1 \mathrm{bar}$ \\
\hline Reflux ratio & 0.015 \\
\hline Condenser duty & $-3.06 \mathrm{GJ} / \mathrm{h}$ \\
\hline Reboiler duty & $3.11 \mathrm{GJ} / \mathrm{h}$ \\
\hline Condensate flowrates & $\begin{array}{l}\text { water: } 74.305 \mathrm{kmol} / \mathrm{h} \\
\text { acetaldehyde: } 0.001 \mathrm{kmol} / \mathrm{h} \\
\text { propylene glycol: } \\
\text { 24dmd: }\end{array}$ \\
\hline Bottoms flowrates & $\begin{array}{l}\text { water: } 0.012 \mathrm{kmol} / \mathrm{h} \\
\text { propylene glycol: } 2.374 \mathrm{kmol} / \mathrm{h}\end{array}$ \\
\hline
\end{tabular}

A summary of the energy consumptions of the four columns involved in the distillative acetaldehyde process is given in Table D-6.

\begin{tabular}{|c|c|}
\hline Column function & Reboiler duty (GJ/h) \\
\hline Reactive distillation: acetalization & 9.40 \\
\hline Acetaldehyde/24dmd separation & 0.61 \\
\hline Reactive distillation: hydrolysis & 3.11 \\
\hline Glycol purification & 0.31 \\
\hline ... TOTAL ... & 13.43 \\
\hline
\end{tabular}

Surnmarizing, the energy input for this reactive distillation process is $13.43 \mathrm{GJ} / \mathrm{h}$, for an ove. I yield of $2.37 \mathrm{kmol} / \mathrm{h}$. 
Downstream processing of simultaneous reaction/extraction equipment

The reaction/extraction equipment in this process was not modeled using ChemCad, but the distillations downstream, in which acetaldehyde is removed from the aqueous and organic streams and $24 \mathrm{dmd}$ is recovered from the extract, were. A $97 \%$ recovery fraction in the extraction was assumed. A large part of the energy spent in the distillation of $20 \mathrm{wt} \%$ acetaldehyde out of the aqueous raffinate was due to the change in sensible heat. For this reason, a bottoms-to-feed heat-exchanger was inserted to improve energy efficiency. A distillation summary is presented in Table D-7.

\begin{tabular}{||l|l||}
\hline \hline Table D-7. Raffinate stripping column \\
\hline \hline Feed composition & $\begin{array}{l}\text { water: } 1000 \mathrm{kmol} / \mathrm{h} \\
\text { acetaldehyde: } 102 \mathrm{kmol} / \mathrm{h}\end{array}$ \\
\hline Number of stages & 20 \\
\hline Feed stage & 10 \\
\hline Condenser specification & total condenser, $\mathrm{R} / \mathrm{D}=0.1$ \\
\hline Reboiler specification & $0.1 \mathrm{kmol} / \mathrm{h}$ acetaldehyde to bottoms \\
\hline Pressure & 1 bar \\
\hline Condenser duty & $-4.63 \mathrm{GJ} / \mathrm{h}$ \\
\hline Reboiler duty & $3.95 \mathrm{GJ} / \mathrm{h}$ \\
\hline Condensate flowrates & $\begin{array}{l}\text { water: } 25.3 \mathrm{kmol} / \mathrm{h} \\
\text { acetaldehyde: } 101.9 \mathrm{kmol} / \mathrm{h}\end{array}$ \\
\hline Bottoms flowrates & $\begin{array}{l}\text { water: } 974.7 \mathrm{kmol} / \mathrm{h} \\
\text { acetaldehyde: } 0.1 \mathrm{kmol} / \mathrm{h}\end{array}$ \\
\hline
\end{tabular}

From data found in Appendix E, it was determined that the lowest volume flow rate of ethylbenzene needed to recover most of the $24 \mathrm{dmd}$ is about half the aqueous volume flow. This was used as the basis for the ChemCad calculations modeling the treatment of the organic extract. In the first column, acetaldehyde is removed and recycled; in the second column, $24 \mathrm{dmd}$ is distilled from the extract, regenerating lean solvent for recycle. The solvent stream is heat-exchanged with the feed to the acetaldehyde-stripping column for increased energy 
efficiency. The reboiler duties for the first and second columns are $0.98 \mathrm{GJ} / \mathrm{h}$ and $2.26 \mathrm{GJ} / \mathrm{h}$, respectively. Distillation summaries are in Tables D-8 and D-9.

\begin{tabular}{|c|c|}
\hline Feed composition & $\begin{array}{l}\text { ethylbenzene: } 74.0 \mathrm{kmol} / \mathrm{h} \\
\text { acetaldehyde: } 14.60 \mathrm{kmol} / \mathrm{h} \\
\text { 24dmd: } 2.91 \mathrm{kmol} / \mathrm{h}\end{array}$ \\
\hline Number of stages & 10 \\
\hline Feed stage & 5 \\
\hline Condenser specification & $\begin{array}{l}\text { partial condenser, } 99 \% \text { of } 24 \mathrm{dmd} \\
\text { retained in bottoms }\end{array}$ \\
\hline Reboiler specification & $\begin{array}{l}99 \% \text { of acetaldehyde recovered in } \\
\text { column top product }\end{array}$ \\
\hline Pressure & $1 \mathrm{bar}$ \\
\hline Reflux ratio & 0.99 \\
\hline Condenser duty & $-0.83 \mathrm{GJ} / \mathrm{h}$ \\
\hline Reboiler duty & $0.98 \mathrm{GJ} / \mathrm{h}$ \\
\hline Condensate flowrates & $\begin{array}{l}\text { ethylbenzene: } 0.01 \mathrm{kmol} / \mathrm{h} \\
\text { acetaldehyde: } 14.45 \mathrm{kmol} / \mathrm{h} \\
\text { 24dmd: } 0.029 \mathrm{kmol} / \mathrm{h}\end{array}$ \\
\hline Bottoms flowrates & $\begin{array}{l}\text { ethylbenzene: } 73.99 \mathrm{kmol} / \mathrm{h} \\
\text { acetaldehyde: } 0.15 \mathrm{kmol} / \mathrm{h} \\
\text { 24dmd: } 2.881 \mathrm{kmol} / \mathrm{h}\end{array}$ \\
\hline
\end{tabular}




\begin{tabular}{|c|c|}
\hline Feed composition & $\begin{array}{l}\text { ethylbenzene: } 73.99 \mathrm{kmol} / \mathrm{h} \\
\text { acetaldehyde: } 0.15 \mathrm{kmol} / \mathrm{h} \\
\text { 24dmd: } 2.881 \mathrm{kmol} / \mathrm{h}\end{array}$ \\
\hline Number of stages & 20 \\
\hline Feed stage & 10 \\
\hline Condenser specification & $\begin{array}{l}\text { total condenser } \\
\text { ethylbenzene fraction } 0.5 \%\end{array}$ \\
\hline Reboiler specification & $\begin{array}{l}99 \% \text { of } 240 \mathrm{md} \text { recovered in } \\
\text { condensate }\end{array}$ \\
\hline Pressure & $1.1 \mathrm{bar}$ \\
\hline Reflux ratio & 21.4 \\
\hline Condenser duty & $-2.13 \mathrm{GJ} / \mathrm{h}$ \\
\hline Reboiler duty & $2.26 \mathrm{GJ} / \mathrm{h}$ \\
\hline Condensate flowrates & $\begin{array}{l}\text { ethylbenzene: } 0.015 \mathrm{kmol} / \mathrm{h} \\
\text { acetaldehyde: } 0.146 \mathrm{kmol} / \mathrm{h} \\
24 \mathrm{dmd}: 2.852 \mathrm{kmol} / \mathrm{h}\end{array}$ \\
\hline Bottoms flowrates & $\begin{array}{l}\text { ethylbenzene: } 73.98 \mathrm{kmol} / \mathrm{h} \\
\text { acetaldehyde: - } \\
24 d \mathrm{dd}: 0.029 \mathrm{kmol} / \mathrm{h}\end{array}$ \\
\hline
\end{tabular}

The $24 \mathrm{dmd}$ is then hydrolyzed in the same way as in the distillative case, with the difference that water must now be added, as the $24 \mathrm{dmd}$ is generated in a water-free state. The reboiler duties for the reactive distillation column and the water/glycol separation column are $0.24 \mathrm{GJ} / \mathrm{h}$ and $0.14 \mathrm{GJ} / \mathrm{h}$, respectively.

A summary of the energy consumptions of the four columns involved in the distillative acetaldehyde process is given in Table D-10. 


\begin{tabular}{|l|c|}
\hline \multicolumn{2}{|l|}{$\begin{array}{l}\text { Tabel D-10. Energy consumptions in the extractive acetaldehyde } \\
\text { process. }\end{array}$} \\
\hline Column function & Reboiler duty (GJ/h) \\
\hline \hline Raffinate stripping & 3.95 \\
\hline Extract stripping & 0.98 \\
\hline Extract distillation & 2.26 \\
\hline Reactive distillation: hydrolysis & 0.24 \\
\hline Glycol purification & 0.14 \\
\hline -- TOTAL -.. & 7.57 \\
\hline
\end{tabular}

Summarizing, the energy input for the downstream processing in this extractive process is $7.57 \mathrm{GJ} / \mathrm{h}$, for an overall yield of $2.84 \mathrm{kmol} / \mathrm{h}$. 
Appendix E. Continuous extraction modelling

\section{Continuous countercurrent reaction/extraction}

In this section differential equations are developed to model the simultaneous reaction and extraction in a continuous countercurrent column.

\section{Nomenctature}

$\mathrm{L}_{2}, \mathrm{~L}_{0} \quad$ volumetric flowrates of aqueous, organic phases

$f$ aqueous volume fraction in column

$c_{a}, c_{\circ} \quad$ concentration of dioxolane in aqueous, organic phases

$c_{g} \quad$ concentration of glycol in aqueous phase

a specific interfacial area (area/volume)

A column cross-sectional area

$\mathrm{H} \quad$ column height

$x \quad$ vertical dimension variable

$r_{\mathrm{a}} \quad$ residence time of aqueous phase

$k_{r}$ pseudo-first order reaction rate constant (time $e^{-1}$ )

$k_{m} \quad$ mass transfer coefficient across phase bcundary

$K_{\text {eq }}, M$ equilibrium constant and its inverse: $M=1 / K_{e q}$

$K_{d m d}, P$ distribution coefficient of $24 d m d$ into the organic phase and its inverse: $P=1 / K_{d m d}$

\section{Assumptions}

* The distribution of both phases and catalyst is uniform throughout the column.

* Both liquids flow through the contactor without axial mixing or radial profiles (plug flow).

* A large excess of acetaldehyde is present, so that the reaction may be considered to be pseudo-first order; the aldehyde concentration is included in $k_{r}$

\section{Differential equations}

$$
L_{a} \frac{d c_{a}}{d x}=k_{p} A f \cdot\left(c_{g}-M c_{a}\right)-k_{m} a A \cdot\left(c_{a}-P c_{o}\right)
$$

Aqueous-phase $24 \mathrm{dmd}$ mass balance: Organic phase $24 \mathrm{dmd}$ mass balance:

$$
L_{0} \frac{d c_{0}}{d x}=-k_{m} a A \cdot\left(c_{a}-P c_{0}\right)
$$

Aqueous-phase glycol mass balance:

$$
L_{a} \frac{d c_{s}}{d x}=-k, A f \cdot\left(c_{s}-M c_{0}\right)
$$

Introducing dimensionless variables:

$$
\xi \equiv x / H, \quad b \equiv c_{a} / c_{g 0}, \quad c \equiv c_{0} / c_{g 0}, \quad d \equiv c_{g} / g_{g 0},
$$


and defining

$\tau_{\mathbf{a}} \equiv \mathrm{A} \cdot \mathrm{H} \cdot \dot{\mathrm{f}} / \mathrm{L}_{\mathrm{a}}$

$S \equiv \mathbf{a} \cdot \mathrm{A} \cdot \mathrm{H}$

the outcome is a set of linear dimensionless differential equations:

$$
\begin{aligned}
& \frac{d b}{d \xi}=k_{r} \tau_{a} \cdot(d-M b)-\frac{k_{m} S}{L_{a}} \cdot(b-P c) \\
& \frac{d c}{d \xi}=\frac{k_{m} S}{L_{0}} \cdot(d-P c) \\
& \frac{d d}{d \xi}=-k_{r} \tau_{a} \cdot(d-M b)
\end{aligned}
$$

These may be solved analytically, which involves solving a third-order linear differential equation of unknown coefficients. It is easier to solve them numerically.

Numeric solution

A program was written in Turbo Pascal to solve the equations using a triple Runge Kutta technique. The equations are solved from the top of the column down; an initial guess is made for the exit concentration of $24 \mathrm{dmd}$ in the organic phase. A second guess is based on the difference between the calculated and true value of the concentration at the bottom of the column. Since the set of differential equations is linear, the true value then follows from interpolation or extrapolation of the two guesses and calculated values.

The program is set up to do sensitivity analyses for a variety of parameters in the model. Some results and the program code are given below. 


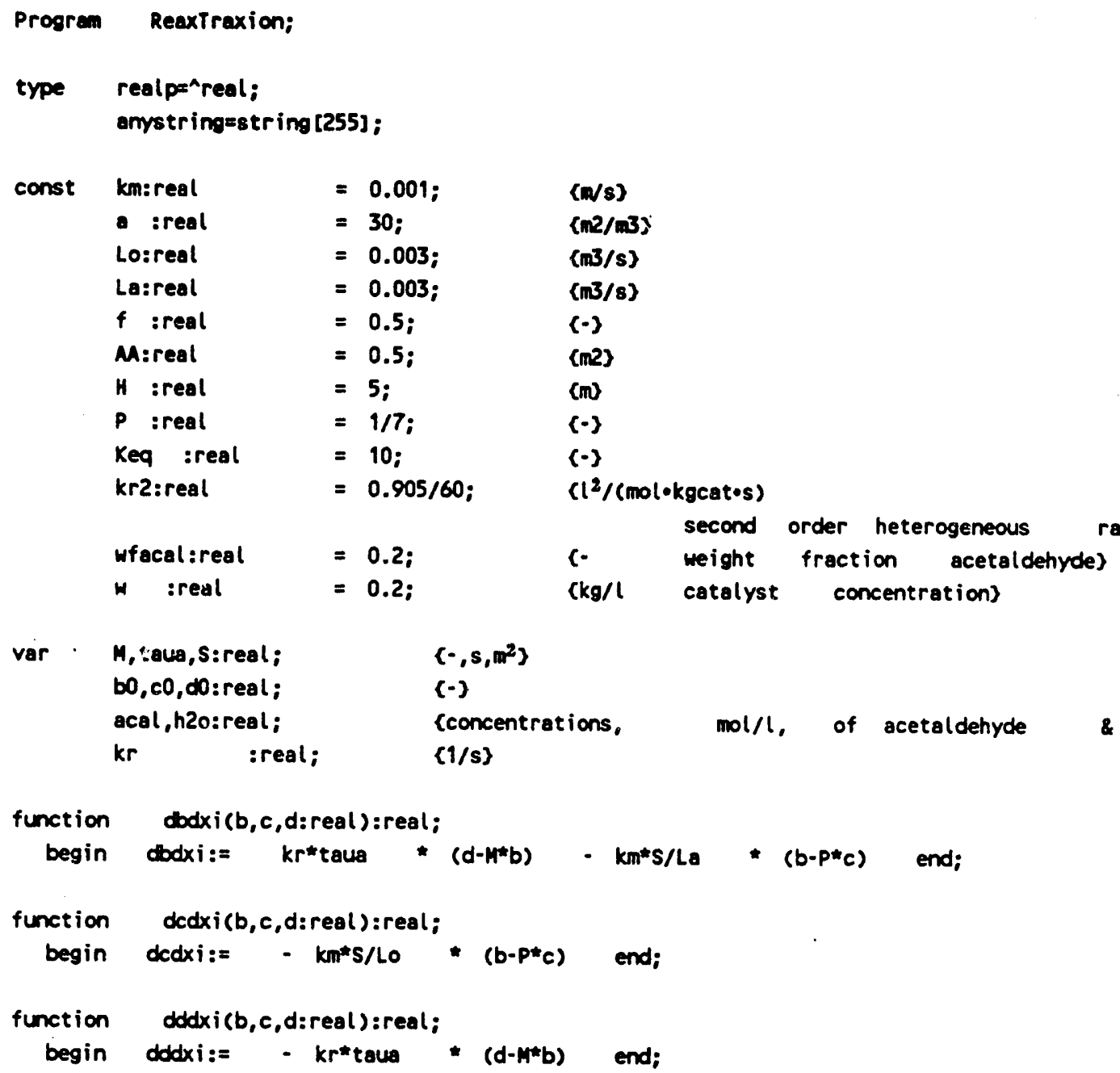

\section{$(-)$}

$\left[-, s, m^{2}\right\}$

(concentrations, mol/l, of acetaldehyde \{1/s\} 


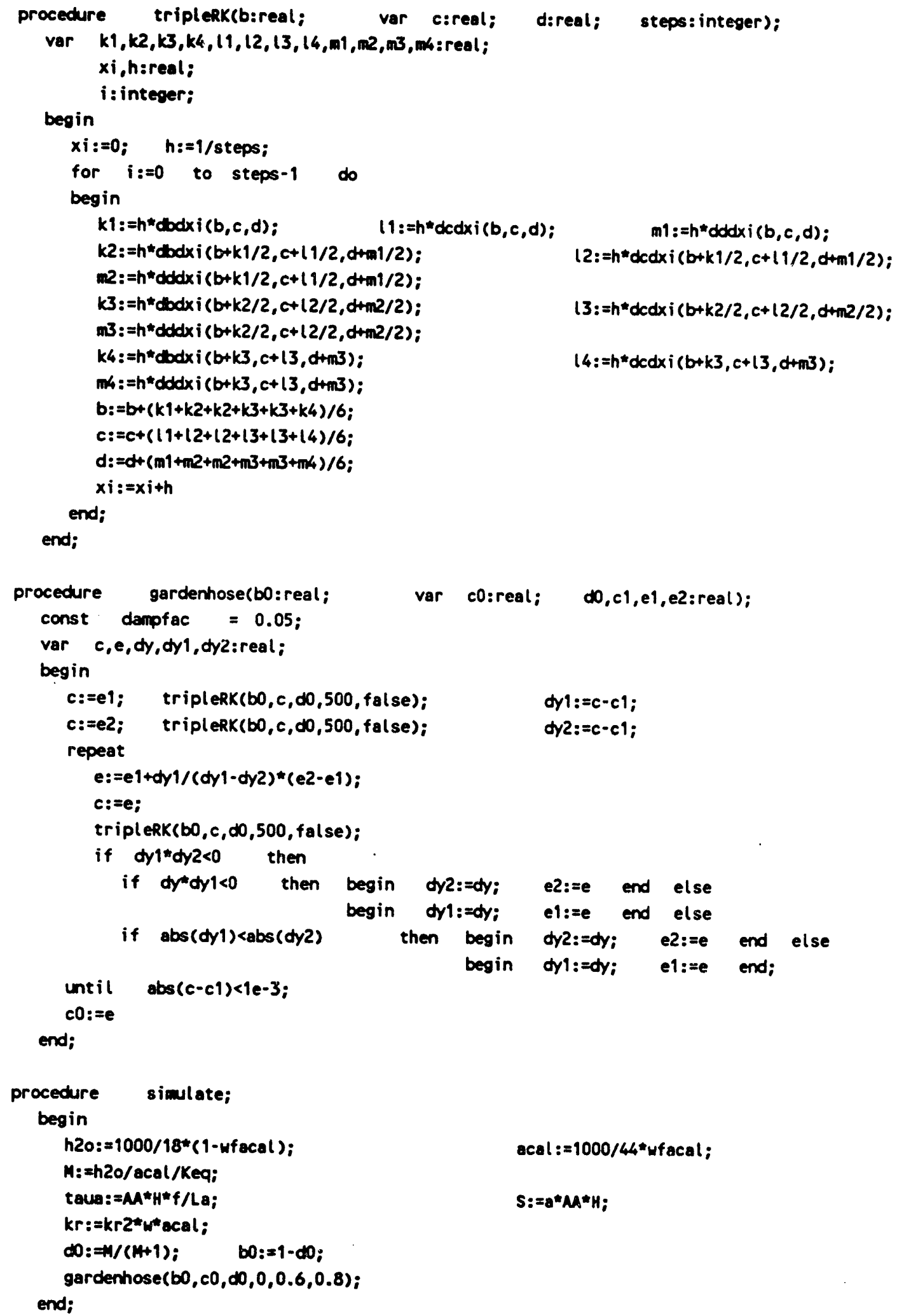




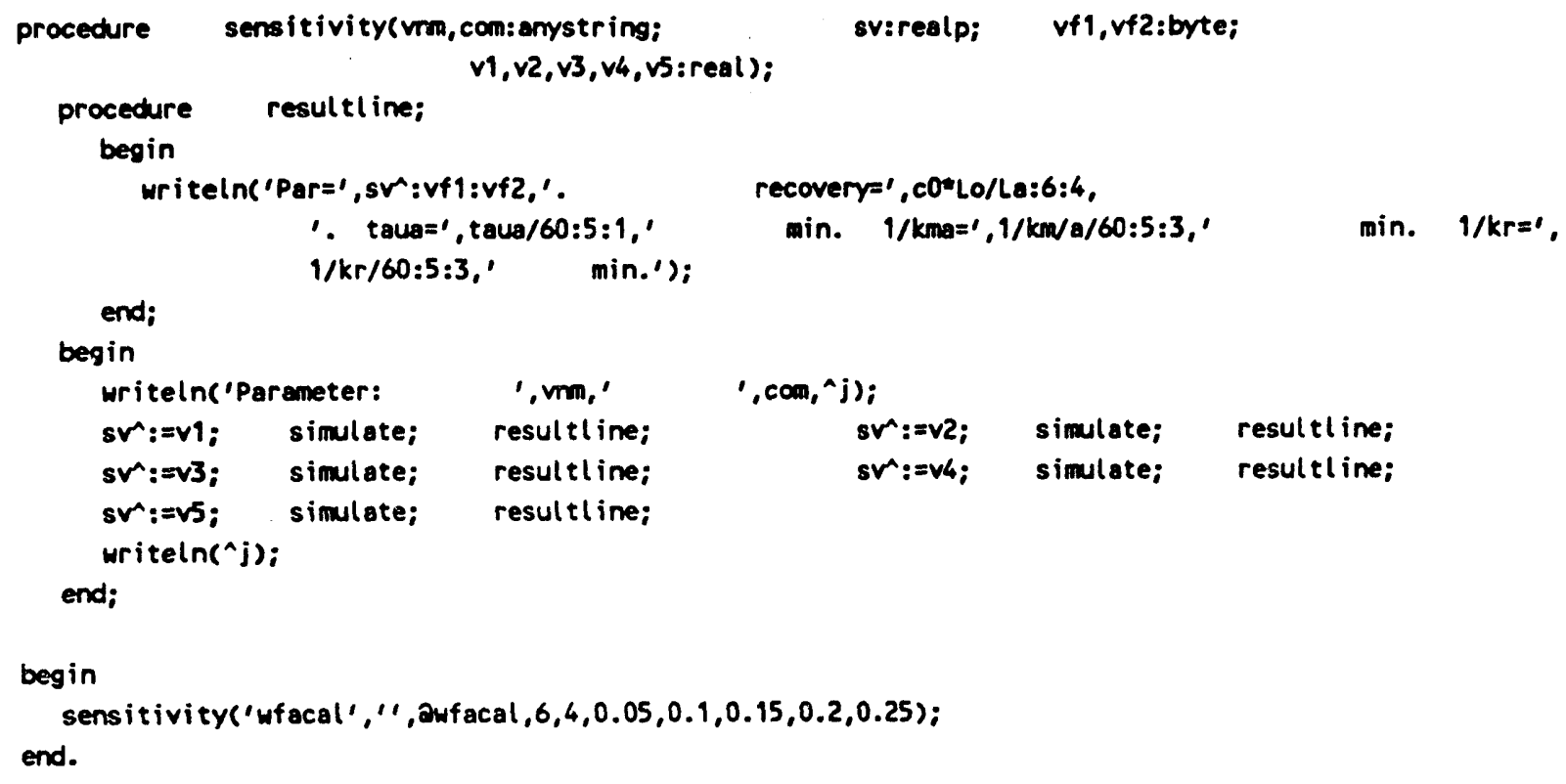


Selected results

In each of the tables below, one of the pertinent parameters was varied from the base case (the base case is given by the constants in the program above). There are clearly three time constants involved in this operation: The column residence time $\tau_{2}$, the reaction time $1 / k_{r}$ and the mass transfer time $1 / \mathrm{k}_{\mathrm{m}} \mathrm{a}$. The values of the time constants are tabulated along with the recovery fraction.

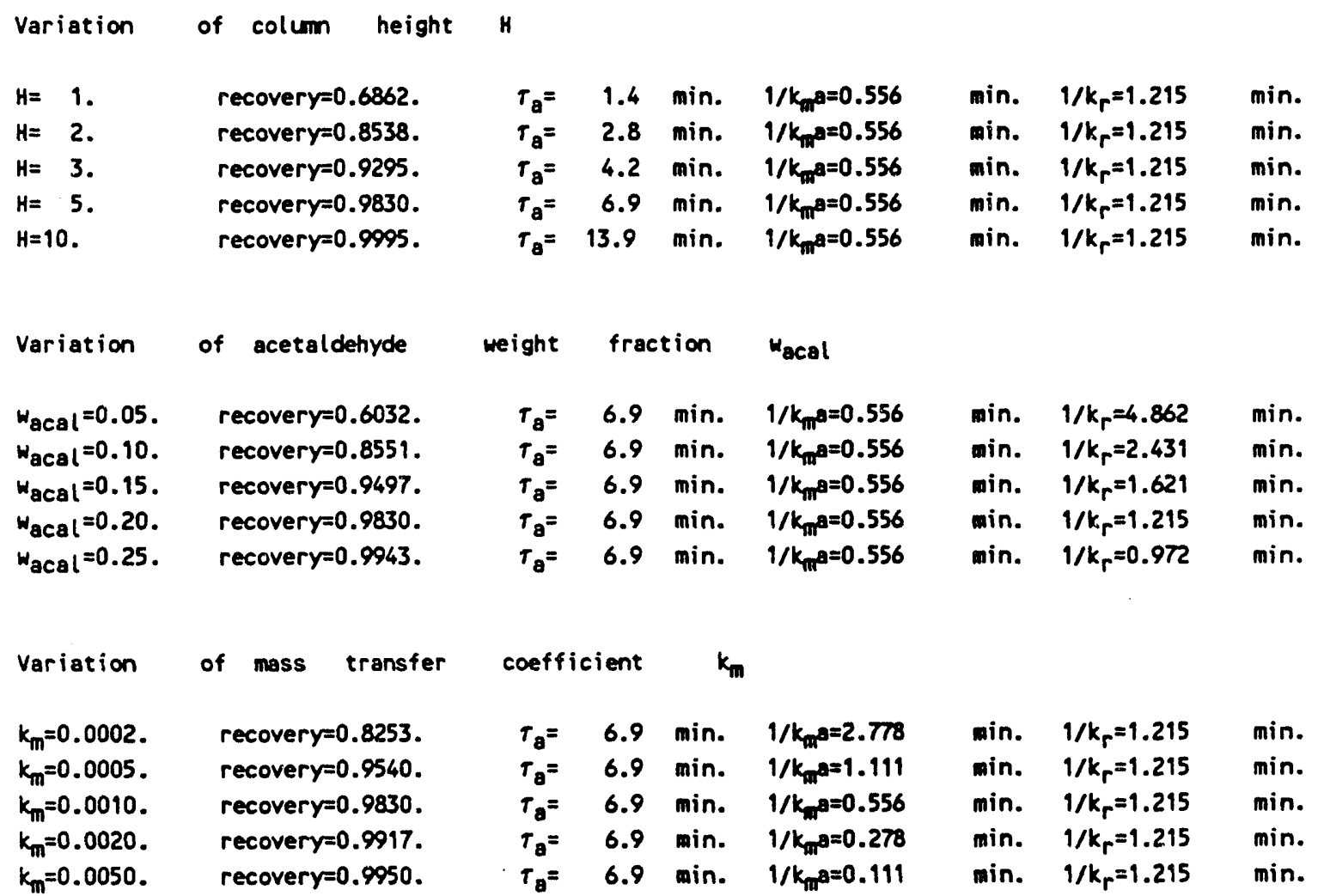

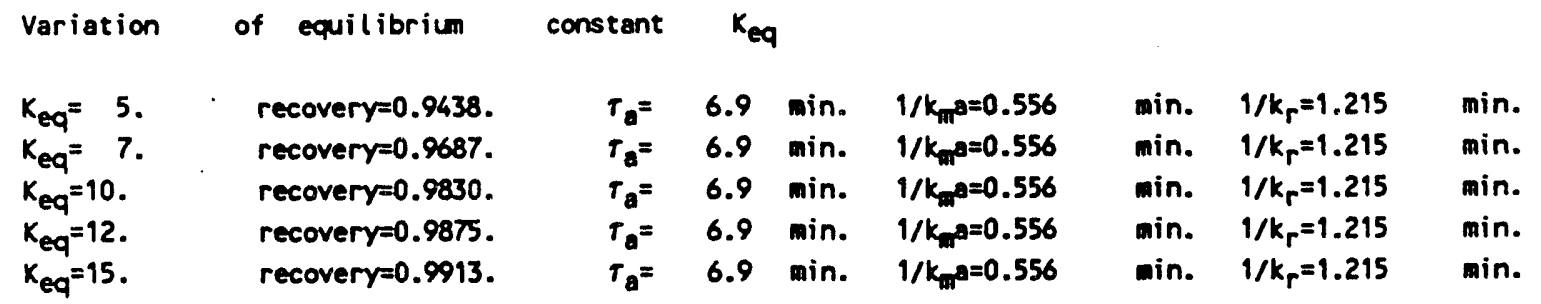

Variation of extractant flowrate $L_{0}$

$L_{0}=0.001$. recovery $=0.9091 . \quad T_{a}=6.9 \mathrm{~min} . \quad 1 / \mathrm{k}_{\operatorname{m}}=0.556$

$L_{0}=0.002$. recovery $=0.9743$. $\quad T_{0}=6.9$ min. $\quad 1 / k_{\text {ma }}=0.556$

$L_{0}=0.003$. recovery $=0.9830$. $T_{\mathrm{a}}=6.9 \mathrm{~min} . \quad 1 / k_{\mathrm{m}} \mathrm{g}=0.556$

$\begin{array}{lllll}\text { recovery }=0.9877 . & T_{\mathrm{a}}= & 6.9 & \text { min. } & 1 / k_{\operatorname{ma}}=0.556 \\ \text { recovery }=0.9899 . & T_{\mathrm{a}}= & 6.9 & \text { min. } & 1 / k_{\operatorname{man}}=0.556\end{array}$

$\begin{array}{lll}\text { min. } & 1 / k_{r}=1.215 & \text { min. } \\ \min & 1 / k_{r}=1.215 & \text { min. } \\ \text { min. } 1 / k_{r}=1.215 & \text { min. } \\ \text { min. } 1 / k_{r}=1.215 & \text { min. } \\ \text { min. } 1 / k_{r}=1.215 & \text { min. }\end{array}$

$l_{0}=0.009$. 


\section{Series of mixer-settlers in countercurrent arrangement}

Continuous countercurrent operation may be difficult to achieve when solid catalyst is present. Therefore, another option was explored, in which the aqueous and organic phases are contacted in a series of mixer-settlers, in overall countercurrent arrangement. The equations governing such a system and their numerical solution are presented below.

Nomenclature (where different from section 1 of this Appendix)

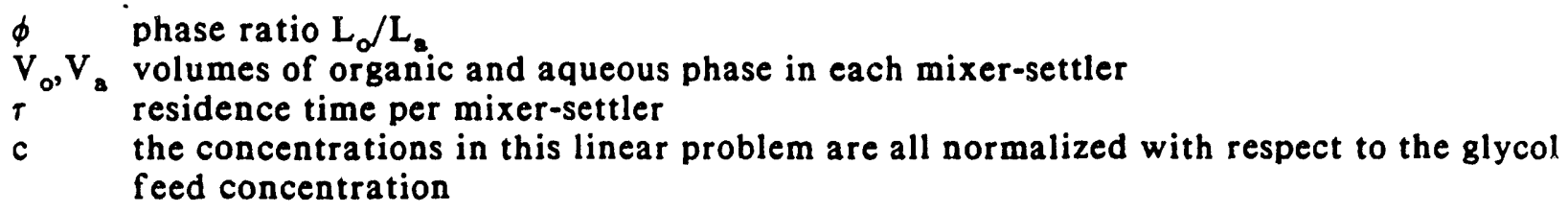

\section{Assumptions}

- As in the continuous countercurrent model, the reaction is assumed to be first-order only in the glycol concentration.

* Extraction equilibrium is satisfied at all times: $Q c_{\mathbf{z}}=c_{0}$.

* The ratio of volumetric flow rates is equal to the phase ratio in each of the mixersettlers: $L_{0} / L_{2}=V_{0} / V_{2}$ and $\tau_{0}=\tau_{2}=\tau$.

* The mixer-settler behaves as a steady state continuous stirred tank reactor.

\section{Mass balances}

For dioxolane: $\mathrm{L}_{0} c_{0}+\mathrm{L}_{\mathrm{a}} c_{\mathrm{a}}=\mathrm{L}_{0} c_{o, \text { in }}+\mathrm{L}_{\mathrm{a}} c_{\mathrm{a}, \text { in }}+\mathrm{V}_{\mathrm{a}} \mathrm{k}_{\mathrm{r}}\left(\mathrm{c}_{\mathrm{g}}-\mathrm{Mc}_{\mathrm{a}}\right)$

For glycol: $\quad \mathrm{L}_{\mathrm{a}} \mathrm{c}_{\mathrm{g}}=\mathrm{L}_{\mathrm{a}} \mathrm{c}_{\mathrm{g}, \text { in }}-\mathrm{V}_{\mathrm{a}} \mathrm{k}_{\mathrm{r}}\left(\mathrm{c}_{\mathrm{g}}-\mathrm{Mc}_{\mathrm{a}}\right)$

When three of the incoming or outgoing concentrations are known, the other three can be calculated. For a series of countercurrent mixer-settlers calculated from the top one to the bottom one, the inputs to each mixer-settler are the aqueous-phase input concentrations and the organic-phase exit concentration. The remaining concentrations may then be calculated from:

$$
\begin{aligned}
& c_{0, \mathrm{bn}}=\frac{c_{0}\left(\frac{1}{Q}+\phi\right)-c_{a \min }-k_{r} \tau\left(c_{\sin }+c_{Q \sin }-\left[\phi+\frac{\mu+1}{Q}\right] c_{0}\right)}{\phi\left(1+k_{r} \tau\right)} \\
& c_{a}=\frac{c_{0}}{Q} \\
& c_{8}=c_{\sin }+\phi\left(c_{a \min }-c_{2}\right)+c_{4 \min }-c_{a}
\end{aligned}
$$

It is now possible to specify a desired recovery fraction for glycol as $24 \mathrm{dmd}$ and calculate stage by stage until the calculated $c_{0}$ becomes less than or equal to zero. The number of stages needed can be calculated in this way as a function of various parameters. A Turbo Pascal program to perform these calculations was developed. The program code and some sample output are given below. The ef fect of aqueous-phase-only plug-flow reactors preceding the series of mixer-settlers or in between stages was investigated and found to not much improve the process. 


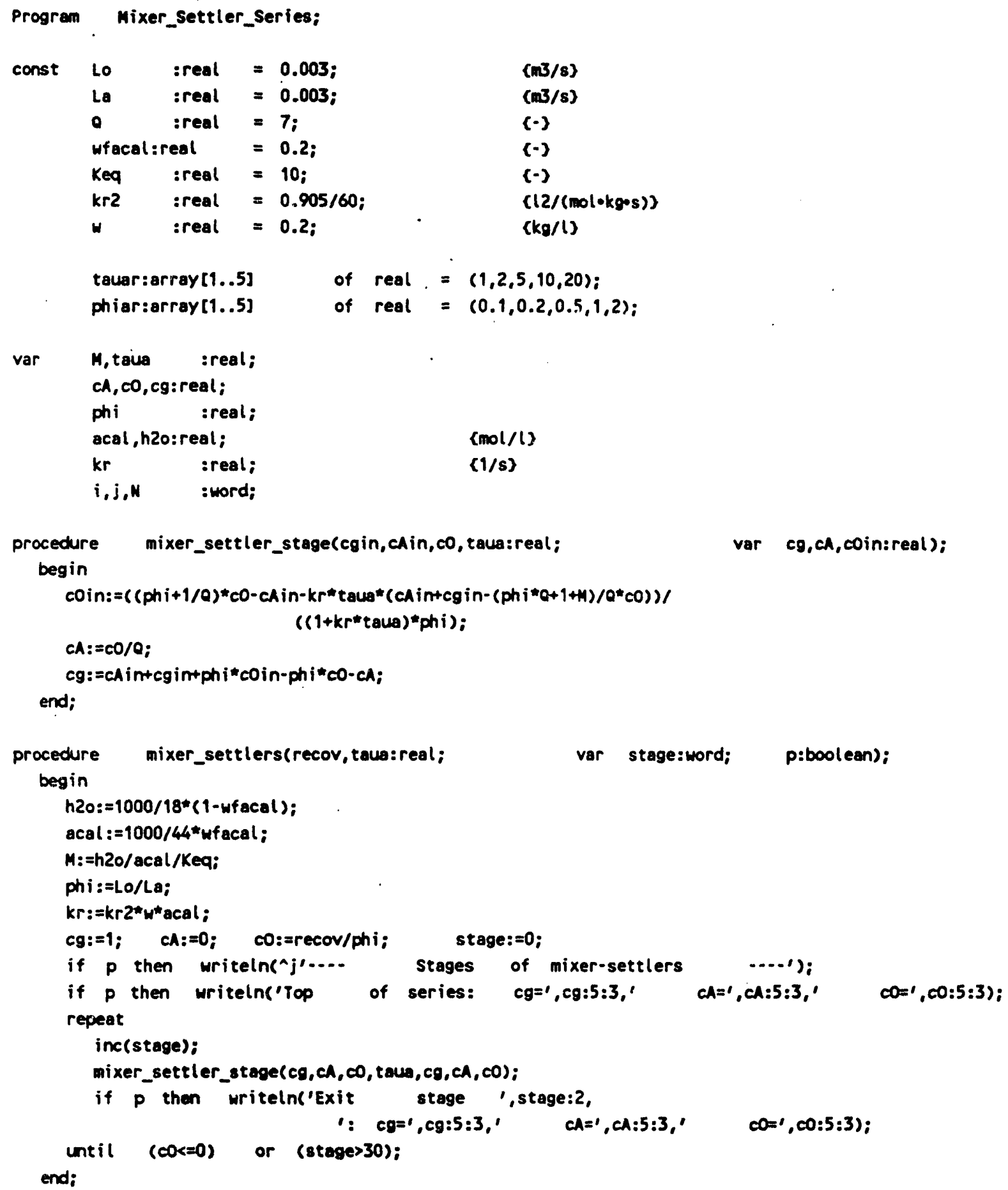




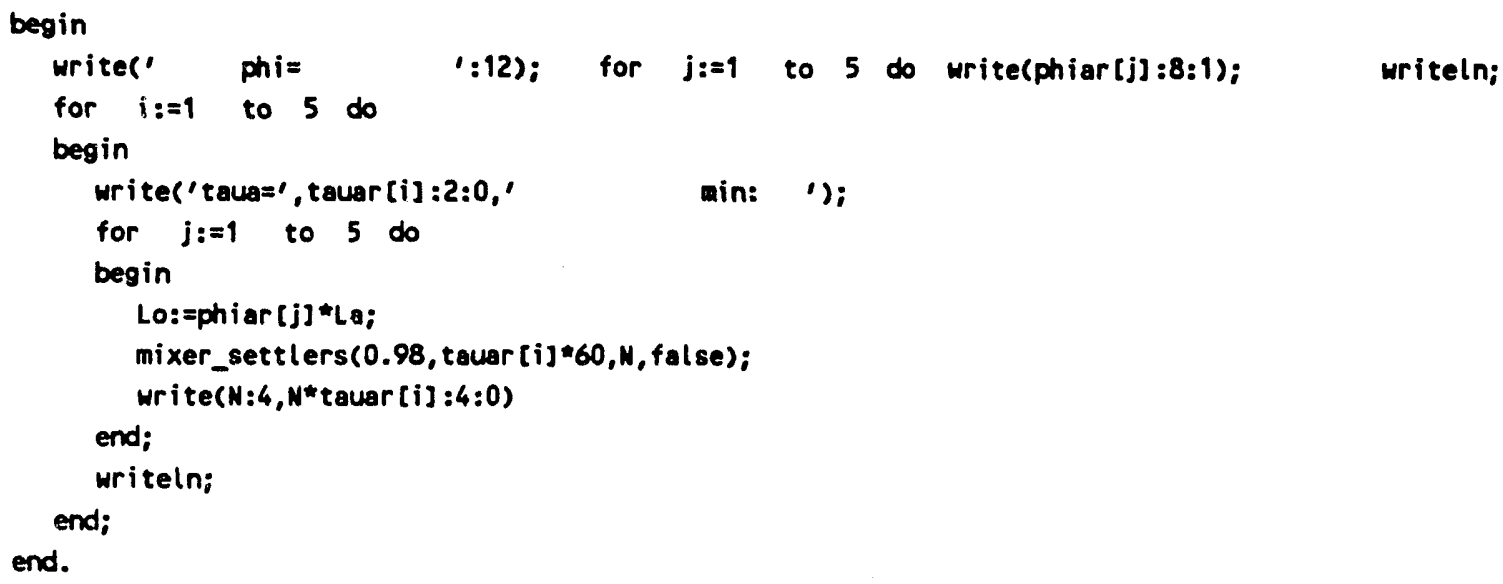

\section{Selected results}

The number of stages required to reach the desired recovery and the total residence time in all stages is tabulated for a number of values of the individual stage residence time, the extractant to feed volume ratio and the desired recovery value.

Desired recovery $95 \%$

\begin{tabular}{|c|c|c|c|}
\hline Volume rati & act & to $\mathrm{aqu}$ & has \\
\hline 0.5 & & & \\
\hline $\begin{array}{ll}\mathbf{T} & \tau_{\text {tot }} \\
(\min )\end{array}$ & $\mathbf{N}$ & ${ }_{\text {tot }}^{\left.T_{\text {min }}\right)}$ & $\mathbf{N}$ \\
\hline
\end{tabular}

$$
\begin{aligned}
& \tau=1 \mathrm{~min} \\
& \tau=2 \mathrm{~min} \\
& \tau=5 \mathrm{~min} \\
& \tau=10 \mathrm{~min}
\end{aligned}
$$

$\begin{array}{rr}9 & 9 \\ 7 & 14 \\ 5 & 25 \\ 5 & 50\end{array}$

$\begin{array}{rr}7 & 7 \\ 5 & 10 \\ 3 & 15 \\ 3 & 30\end{array}$

$\begin{array}{rr}6 & 6 \\ 4 & 8 \\ 3 & 15 \\ 2 & 20\end{array}$

Desired recovery $98 \%$

$$
\begin{aligned}
& \tau=1 \mathrm{~min} \\
& \tau=2 \mathrm{~min} \\
& \tau=5 \mathrm{~min} \\
& \tau=10 \mathrm{~min}
\end{aligned}
$$

$12 \quad 12$

$9 \quad 18$

$7 \cdot 35$

$7 \quad 70$

$\begin{array}{rr}9 & 9 \\ 6 & 12 \\ 4 & 20 \\ 4 & 40\end{array}$

$\begin{array}{rr}8 & 8 \\ 5 & 10 \\ 4 & 20 \\ 3 & 30\end{array}$

Desired recovery $99 \%$

$$
\begin{aligned}
& \tau=1 \mathrm{~min} \\
& \tau=2 \mathrm{~min} \\
& \tau=5 \mathrm{~min} \\
& \tau=10 \mathrm{~min}
\end{aligned}
$$$$
15
$$

$$
15
$$$$
22
$$

945

$8 \quad 80$

$\begin{array}{rr}10 & 10 \\ 7 & 14 \\ 5 & 25 \\ 4 & 40\end{array}$

$\begin{array}{rr}9 & 9 \\ 6 & 12 \\ 4 & 20 \\ 3 & 30\end{array}$




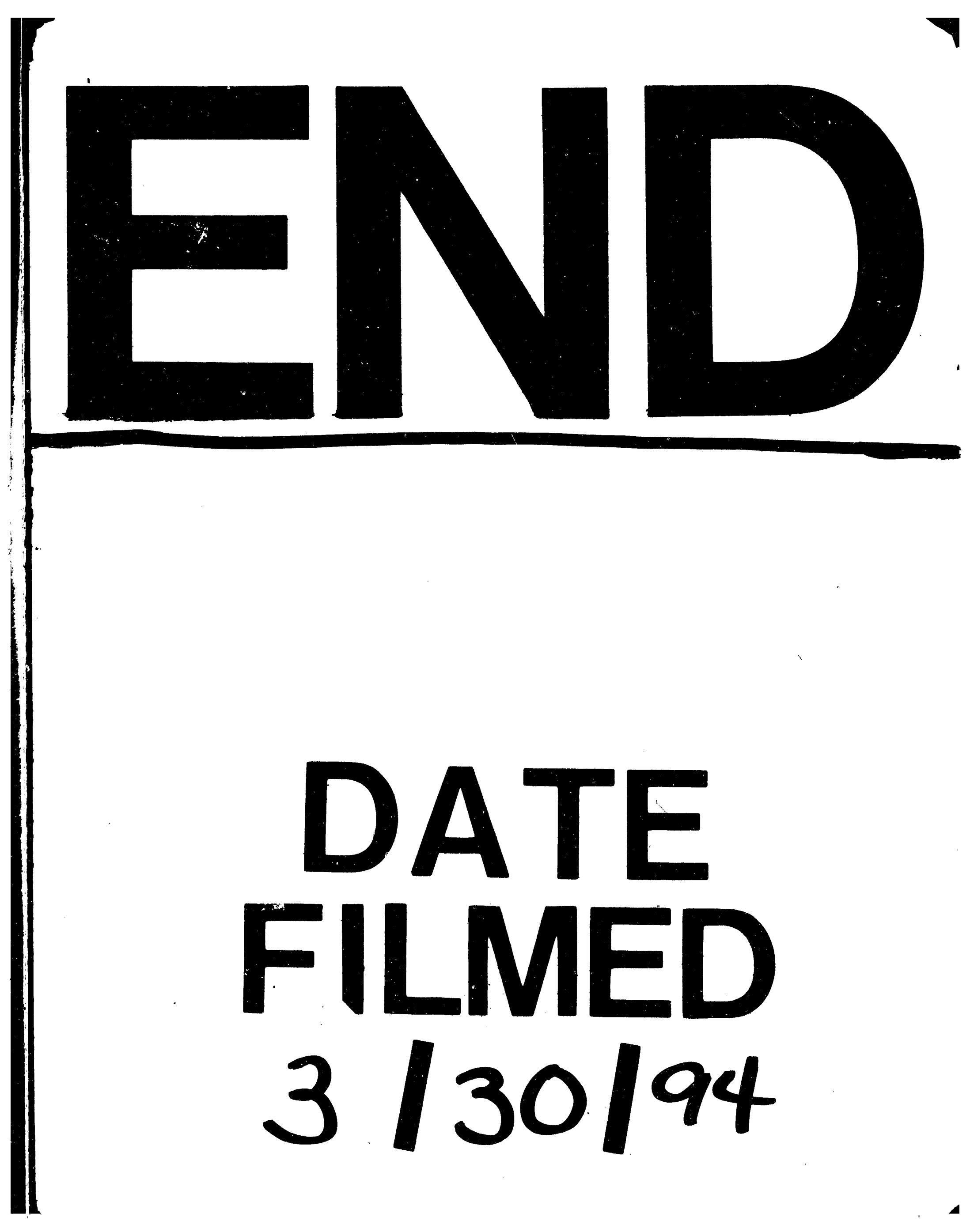


